Research Article

\title{
State Estimation Based on Sigma Point Kalman Filter for Suspension System in Presence of Road Excitation Influenced by Velocity of the Car
}

\author{
Chi Nguyen Van (iD \\ Thai Nguyen University of Technology (TNUT), Institute of High-Technology Research and Development for Industry (RIAT),
} 3/2 Street, Thai Nguyen 23000, Vietnam

Correspondence should be addressed to Chi Nguyen Van; ngchi@tnut.edu.vn

Received 7 June 2019; Revised 31 July 2019; Accepted 12 August 2019; Published 3 November 2019

Academic Editor: Radek Matušů

Copyright (c) 2019 Chi Nguyen Van. This is an open access article distributed under the Creative Commons Attribution License, which permits unrestricted use, distribution, and reproduction in any medium, provided the original work is properly cited.

The states of the suspension system including the road excitation depend on the road quality, the velocity of the car, and the sprung mass. Those states play a very important role in the control problem of stability, ride comfort, ride safety, and dynamic wheel load of the suspension systems. The velocities and deflections of the sprung mass and unsprung mass would not be measured fully in the practice. Therefore, it must be estimated by other measured quantities from the system such as acceleration and deflection of sprung mass and unsprung mass. To control the active suspension system, its states need to be estimated accurately and guaranteed the response time. This paper presents the method using the sigma point Kalman filter to estimate the suspension system's states including the road excitation, the deflections, and the velocities of the sprung mass and unsprung mass. The mathematical model of the suspension system is rewritten for the state estimation problem, and the stochastic load profile is supposed the main noise input. The stochastic characteristic of the road excitation depending on the car's velocity is taken into account in the model used for suspension system state estimation. The results calculated based on the practical experiment data for specific road profile with some particular velocities of the car show that the suspension system states are estimated quite accurately in comparison with the practice states.

\section{Introduction}

In recent years, the research in active suspension control has continued to advance with respect to its capability of driving flexibly the suspension damping and suspension spring stiffness to guarantee the ride comfort [1-4]. This work considers a typical active suspension system with the notations of the quantities depicted in Figure 1.

The mechanical system consists of sprung mass $m_{\mathrm{s}}$ and unsprung mass $m_{\mathrm{w}}$, and the sprung mass and unsprung mass are connected by the suspension part including damping part $c_{\mathrm{s}}$ and spring part $d_{\mathrm{s}}$ in parallel. In case of active suspension, this part is added by an active actuator (electrical, electromagnetic, and hybrid devices driven by electrical signal $u(t)$ ) to change the natural characteristics of suspension part in order to get the desired ride comfort. Connection between the unsprung mass and the road surface is the wheel. The wheel is described by wheel damping part $c_{\mathrm{w}}$ and wheel spring part $d_{\mathrm{w}}$. The states of the suspension system are deflections, velocities, and accelerations of sprung mass $z_{\mathrm{s}}, \dot{z}_{\mathrm{s}}, \ddot{z}_{\mathrm{s}}$ and unsprung mass $z_{\mathrm{s}}, \dot{z}_{\mathrm{s}}, \ddot{z}_{\mathrm{s}}$, respectively. $z_{\mathrm{r}}$ is the road excitation supported as the main input noise of the system; $z_{\mathrm{r}}$ depends on the road profile and velocity of the car $v(t)$.

The performance quality of the suspension system is reflected upon the comfort ride, and this quality is presented by 3 parameters: the accelerations of the car and the wheel $\ddot{z}_{\mathrm{s}}, \ddot{z}_{\mathrm{c}}$, respectively; the dynamic wheel load $F_{\mathrm{d}}$ and the suspension deflection $z_{\mathrm{s}}-z_{\mathrm{w}}$. The dynamic wheel load $F_{\mathrm{d}}$ is calculated as follows:

$$
F_{\mathrm{d}}=c_{\mathrm{w}}\left(z_{\mathrm{r}}-z_{\mathrm{w}}\right)+d_{\mathrm{w}}\left(\dot{z}_{\mathrm{r}}-\dot{z}_{\mathrm{w}}\right)[\mathrm{N}] \text {. }
$$

The dynamic wheel load $F_{\mathrm{d}}$ depends on the mass of the car $m_{c}$, velocity of the car $v$, and road profile as shown in Figures 2 and 3. 


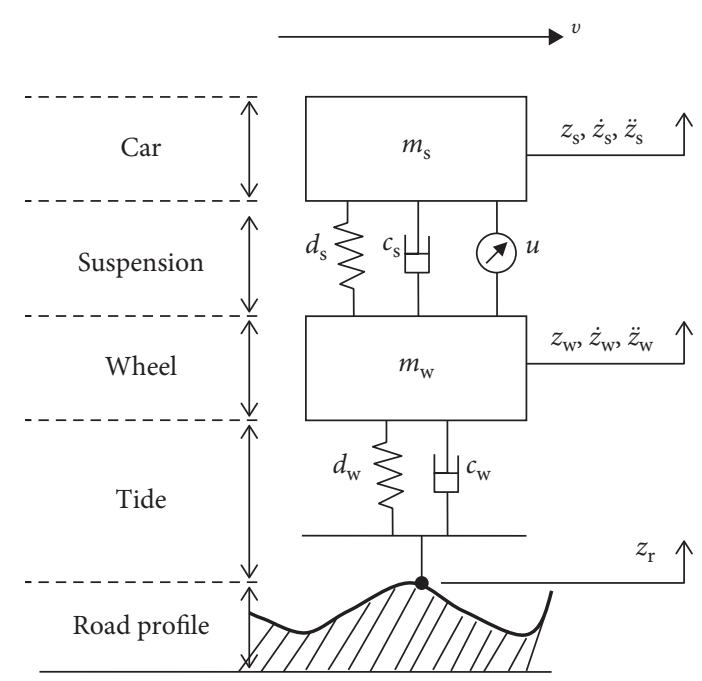

Figure 1: Physical model of a typical suspension system.

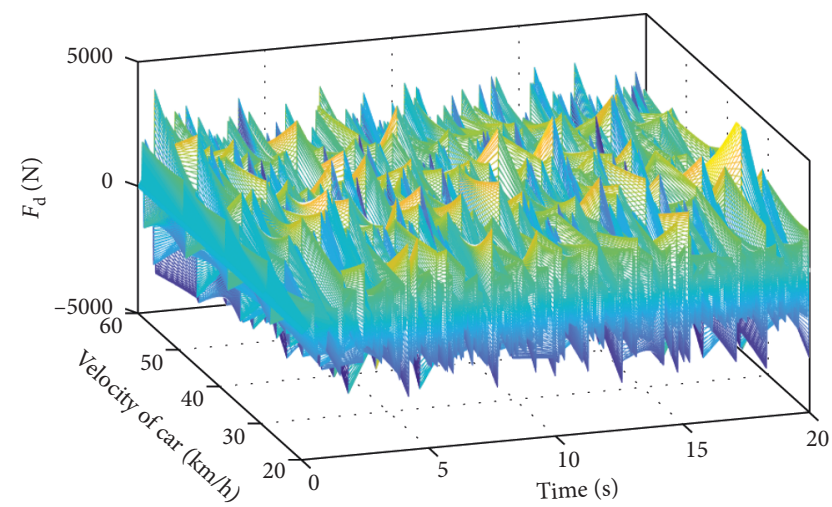

Figure 2: The variation of the dynamic wheel load with the variation of the car velocity for the specific road profile.

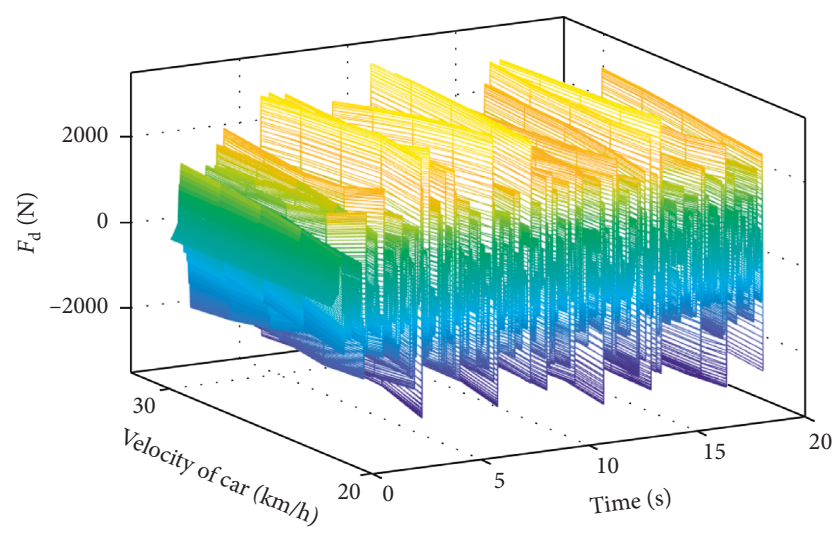

Figure 3: The variation of the dynamic wheel load with the variation of the car mass.

The smaller values of $\ddot{z}_{\mathrm{s}}, \ddot{z}_{\mathrm{c}}, F_{\mathrm{d}}$ are, the higher comfort ride of the passengers in the car is. To control actuator of active suspension system in order to get the desired values of $\ddot{z}_{\mathrm{s}}, \ddot{z}_{\mathrm{c}}, F_{\mathrm{d}}$ with the measured qualities $\ddot{z}_{\mathrm{w}}, \ddot{z}_{\mathrm{s}}, z_{\mathrm{s}}-z_{\mathrm{w}}$, all the states $z_{\mathrm{r}}, z_{\mathrm{w}}, z_{\mathrm{s}}, \dot{z}_{\mathrm{w}}, \dot{z}_{\mathrm{s}}, F_{\mathrm{d}}$ need to be estimated by using the state estimation. There are a lot of state estimation methods to implement this problem in some materials [5-8] in the literature; most of them now use the Kalman Filters (KF) and extended Kalman filter (EKF) for some modified models of the suspension systems. The state estimation quality is dependent of the road profile, velocity of the car $v(t)$, and the mass of sprung $m_{\mathrm{s}}$.

The road excitation always is supposed as the main input noise, but we realize that $z_{\mathrm{r}}$ not only depends on the road profile but also on the velocity of the car. For the same road profile, as the velocity of the car changes, the stochastic characteristics of the $z_{\mathrm{r}}$ will be changed.

Figure 4 shows the varying of the $z_{\mathrm{r}}$ in the case velocity of the car changing from $5 \mathrm{~km} / \mathrm{h}$ to $45 \mathrm{~km} / \mathrm{h}$ for the same road profile. The road profile has stochastic characteristics as follows: $\min =-0.0232 \mathrm{~cm} ; \max =0.0235 \mathrm{~m}$; mean $=$ $0.00131 \mathrm{~m}$; variance $=0.033 \mathrm{~m} ; \mu=0.00131 \mathrm{~m} ; \sigma=0.058 \mathrm{~m}$.

Figure 4 shows that the velocity of the car is higher and the amplitude of the variation $z_{\mathrm{r}}$ is lower. The maximum of $z_{\mathrm{r}}$ is $0.06 \mathrm{~m}$ in the case $v(t)=5 \mathrm{~km} / \mathrm{h}$, and the maximums of $z_{\mathrm{r}}$ are $0.023 \mathrm{~m}$ and $0.02 \mathrm{~m}$ in the cases $v(t)=15 \mathrm{~km} / \mathrm{h}$ and $45 \mathrm{~km} / \mathrm{h}$, respectively.

The changing of stochastic characteristics $z_{\mathrm{r}}$ by the velocity of the car and road profile will affect strongly to the state estimation process.

This paper presents the method using the SPKF to estimate the suspension system's states. The system model taking into account the road excitation model and velocity of the car is used in the SPKF algorithm. Statistical characteristics of the road excitation are updated in SPKF by using the correlation matrices depending on the velocity of the car. The results calculated by the using the practical data for particular road profile with some specific velocities of the car show that the suspension system's states are estimated quite accurately in comparison with the real states. The remaining part of this paper is structured as follows: Section 2 mentions the modelling of the suspension system. Section 3 introduces the method using SPKF to estimate the states of the suspension systems. Section 4 shows the estimated states calculated by using the practical data for particular road profile with some specific velocities of the car. Finally, Section 5 summarizes some conclusions.

\section{Modelling of the Suspension System}

The first-order model of the road excitation $z_{\mathrm{r}}$ as the function of the road profile and velocity of the car depicted in Figure 5 can be written as $[9,10]$ :

$$
\frac{d z_{\mathrm{r}}}{d t}=-\lambda v z_{\mathrm{r}}+w_{\mathrm{zr}}
$$

where $\lambda$ and $v$ are the optional feedback parameter and velocity of the car, respectively, and $w_{\mathrm{zr}}$ is the input noise caused by the road profile. 


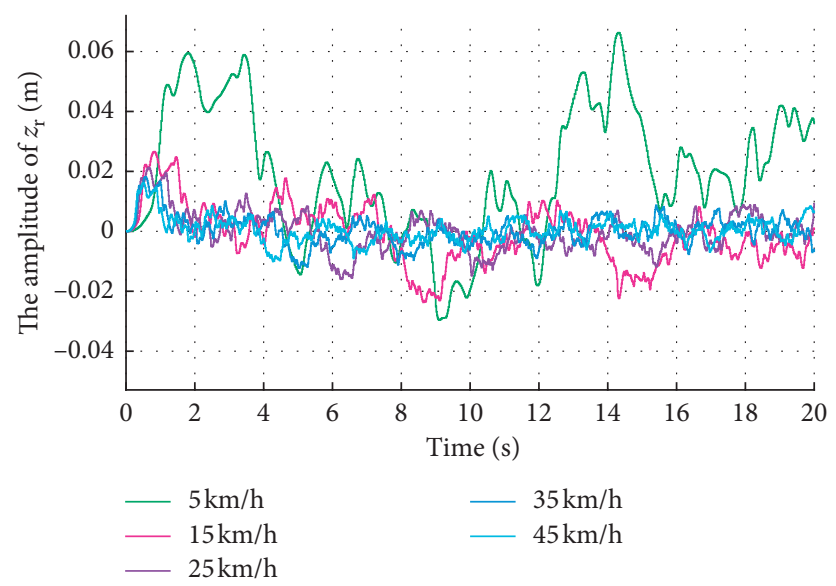

FIgURE 4: The variation of $z_{\mathrm{r}}$ with the velocity of the car for the same road profile.

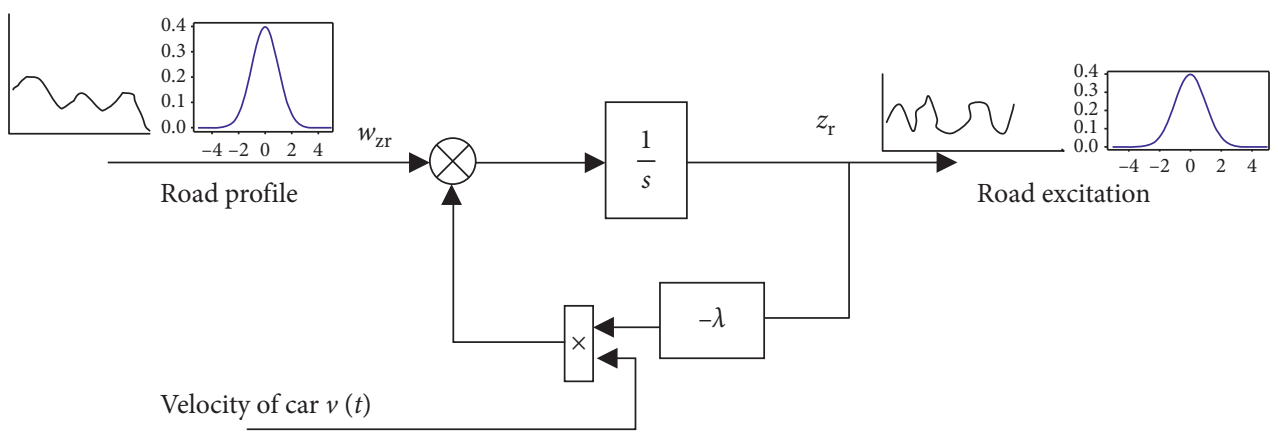

FiguRE 5: The first-order model of road excitation $z_{\mathrm{r}}$ as the function of the road profile and velocity of the car.

Most of estimators using in the materials [11, 12] consider $z_{\mathrm{r}}$ as the input noise acting directly to the systems, and the model of $z_{\mathrm{r}}$ related to the road profile and velocity of the car is not taken into account in the model of the system. So, to describe all the states of the system including the road profile and road excitation, the model of the active suspension system needs to be mentioned in the relationship in equation (2).

Let us consider the state vector of the suspension system described in Figure 1 as

$$
\begin{aligned}
z_{1} & =z_{\mathrm{s}}, \\
z_{2} & =\dot{z}_{\mathrm{s}}, \\
z_{3} & =z_{\mathrm{w}}, \\
z_{4} & =\dot{z}_{\mathrm{w}}, \\
z_{5} & =z_{\mathrm{r}}, \\
z_{6} & =\dot{z}_{\mathrm{r}} \\
\underline{z} & =\left[\begin{array}{llllll}
z_{1} & z_{2} & z_{3} & z_{4} & z_{5} & z_{6}
\end{array}\right]^{T} .
\end{aligned}
$$

Suppose $u(t)$ as the active force, if $u(t)=0$, the system is called the passive suspension system, else it is called the active suspension system, when $u(t) \neq 0$. The model of the suspension system is written as follows:

$$
\frac{d \underline{z}}{d t}=\left\{\begin{array}{l}
z_{2}+w_{\mathrm{zs}}, \\
\frac{c_{\mathrm{s}}\left(z_{3}-z_{1}\right)}{m_{\mathrm{s}}}-\frac{d_{\mathrm{c}}\left(z_{2}-z_{4}\right)}{m_{\mathrm{s}}}+\frac{u(t)}{m_{\mathrm{c}}}+w_{\mathrm{dzs}}, \\
z_{4}+w_{\mathrm{zw}}, \\
\frac{c_{\mathrm{w}}\left(z_{5}-z_{3}\right)}{m_{\mathrm{w}}}-\frac{d_{\mathrm{w}}\left(\lambda v z_{5}+z_{4}\right)}{m_{\mathrm{w}}}-\frac{c_{\mathrm{s}}\left(z_{3}-z_{1}\right)}{m_{\mathrm{w}}} \\
\quad+\frac{d_{\mathrm{c}}\left(z_{2}-z_{4}\right)}{m_{\mathrm{w}}}-\frac{u(t)}{m_{\mathrm{w}}}+w_{\mathrm{dzw}}, \\
z_{6}+w_{\mathrm{zr}}, \\
-\lambda v z_{5}+w_{\mathrm{dzr}} .
\end{array}\right.
$$

Equation (4) is written briefly as follows:

$$
\frac{d \underline{z}}{d t}=\mathbf{f}(\underline{z}(t))+\mathbf{g}(\underline{z}(t)) \mathbf{u}(t)+\mathbf{w}(t)
$$

in which the state functions and vectors are defined as follows: 


$$
\begin{aligned}
& \mathbf{f}(\underline{z}(t))=\left[\begin{array}{c}
z_{2} \\
\frac{c_{\mathrm{s}}\left(z_{3}-z_{1}\right)}{m_{\mathrm{s}}}-\frac{d_{\mathrm{c}}\left(z_{2}-z_{4}\right)}{m_{\mathrm{s}}} \\
z_{4} \\
\frac{c_{\mathrm{w}}\left(z_{5}-z_{3}\right)}{m_{\mathrm{w}}}-\frac{d_{\mathrm{w}} z_{4}}{m_{\mathrm{w}}}-\frac{c_{\mathrm{s}}\left(z_{3}-z_{1}\right)}{m_{\mathrm{w}}}+\frac{d_{\mathrm{c}}\left(z_{2}-z_{4}\right)}{m_{\mathrm{w}}} \\
z_{6} \\
0
\end{array}\right] \\
& \mathbf{g}(\underline{z}(t))=\left[\begin{array}{cc}
0 & 0 \\
\frac{1}{m_{\mathrm{c}}} & 0 \\
0 & 0 \\
\frac{-1}{m_{\mathrm{w}}} & \frac{-d_{\mathrm{w}} \lambda z_{\mathrm{r}}}{m_{\mathrm{w}}} \\
0 & 0 \\
0 & -\lambda z_{5}
\end{array}\right], \\
& \mathbf{w}(t)=\left[\begin{array}{c}
w_{\mathrm{zs}} \\
w_{\mathrm{dzs}} \\
w_{\mathrm{zw}} \\
w_{\mathrm{dzw}} \\
w_{\mathrm{zr}} \\
w_{\mathrm{dzr}}
\end{array}\right], \\
& \mathbf{u}(t)=\left[\begin{array}{l}
u(t) \\
v(t)
\end{array}\right] .
\end{aligned}
$$

The vector $\mathbf{f}(\underline{z}(t))$ reflects the natural dynamic of the suspension system, and the matrix $\mathbf{g}(\underline{z}(t))$ converts the road excitation; active force and velocity of the car to the vibrations of the sprung mass and unsprung mass describe the relationship between the road excitation with road profile and velocity of the car. The dynamic noise vector is $\mathbf{w}(t)$, in which four first elements are the noises of the states $z_{\mathrm{s}}, \dot{z}_{\mathrm{s}}, z_{\mathrm{w}}, \dot{z}_{\mathrm{w}}$ caused by the errors of the model parameters like the changing of the mass $m_{\mathrm{s}}$ of the car (Figures 6 and 7) and the last two elements are the noises caused by the road profile and velocity of the car $w_{\mathrm{zr}}, w_{\mathrm{dzr}}$. By the characteristics of the road and system, $\mathbf{w}(t)$ is Gauss white noise and satisfies the equation $E\left\{\mathbf{w}(t) \mathbf{w}(t)^{\prime}\right\}=Q \delta\left(t-t^{\prime}\right)$, where $Q$ is the positive defined matrix.

The measured signals of the suspension are accelerations of the sprung mass, unsprung mass, and the deflection between the sprung mass and unsprung mass. The output of the model is formed as vector as follows:

$$
\underline{y}=\left[\begin{array}{lll}
\ddot{z}_{\mathrm{s}} & \ddot{z}_{\mathrm{w}} & z_{\mathrm{s}}-z_{\mathrm{w}}
\end{array}\right]^{T} .
$$

The model of the output vector is

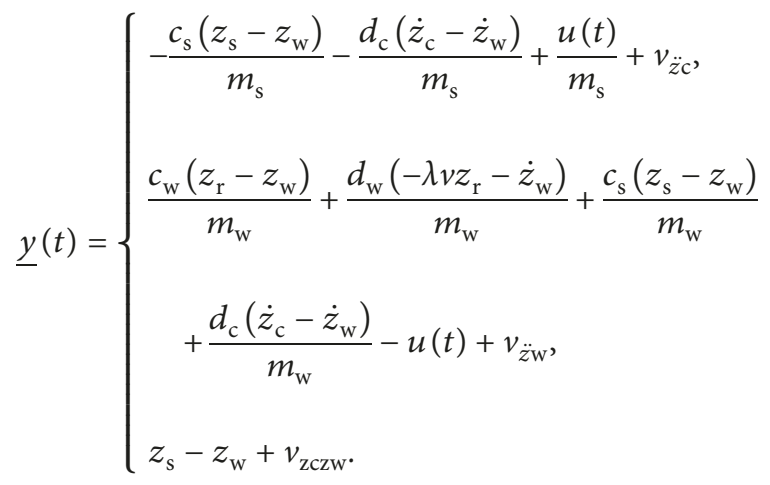

The equation (8) is written briefly as

$$
\underline{y}(t)=\mathbf{h}(\underline{z}(t))+\zeta(\underline{z}(t)) \mathbf{u}(t)+\mathbf{n}(t)
$$

where

$$
\begin{aligned}
\mathbf{h}(\underline{z}(t)) & =\left[\begin{array}{c}
-\frac{c_{\mathrm{s}}\left(z_{\mathrm{s}}-z_{\mathrm{w}}\right)}{m_{\mathrm{s}}}-\frac{d_{\mathrm{c}}\left(\dot{z}_{\mathrm{c}}-\dot{z}_{\mathrm{w}}\right)}{m_{\mathrm{s}}} \\
\frac{c_{\mathrm{w}}\left(z_{\mathrm{r}}-z_{\mathrm{w}}\right)}{m_{\mathrm{w}}}-\frac{d_{\mathrm{w}}}{m_{\mathrm{w}}} \dot{z}_{\mathrm{w}}+\frac{c_{\mathrm{s}}\left(z_{\mathrm{s}}-z_{\mathrm{w}}\right)}{m_{\mathrm{w}}}+\frac{d_{\mathrm{c}}\left(\dot{z}_{\mathrm{c}}-\dot{z}_{\mathrm{w}}\right)}{m_{\mathrm{w}}} \\
z_{\mathrm{s}}-z_{\mathrm{w}}
\end{array}\right], \\
\zeta(\underline{z}(t)) & =\left[\begin{array}{cc}
\frac{1}{m_{\mathrm{s}}} & 0 \\
-\frac{1}{m_{\mathrm{w}}}-\frac{d_{\mathrm{w}} \lambda z_{\mathrm{r}}}{m_{\mathrm{w}}} \\
0 & 0
\end{array}\right],
\end{aligned}
$$

$$
\mathbf{n}(t)=\left[\begin{array}{c}
v_{\ddot{z} \mathrm{c}} \\
v_{\ddot{z} \mathrm{w}} \\
v_{\mathrm{zczw}}
\end{array}\right] \text {. }
$$

The vector $\mathbf{h}(\underline{z}(t))$ is the natural output of the system and the matrix $\zeta(\underline{z}(t))$ describes the effects of velocity and active force to the accelerations and deflections of sprung and unsprung masses. Vector $\mathbf{n}(t)$ is the output noise caused by the changing of the sprung mass and the spring stiffness. $\mathbf{n}(t)$ is Gauss white noise and satisfies the equation 


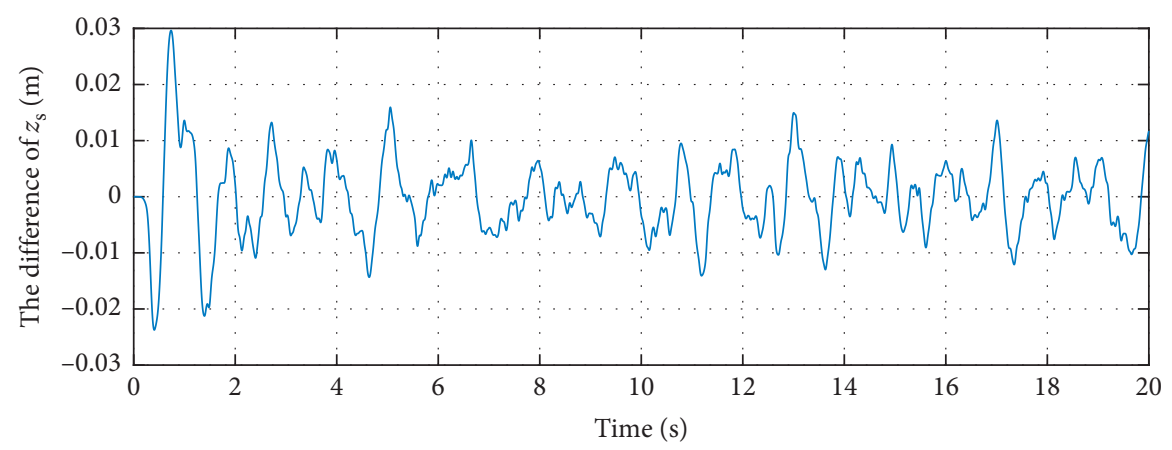

Figure 6: The difference of $z_{\mathrm{s}}$ between two cases of $m_{\mathrm{s}}=94 \mathrm{~kg}$ and $m_{\mathrm{s}}=144 \mathrm{~kg}$ for same road profile and velocity of the car.

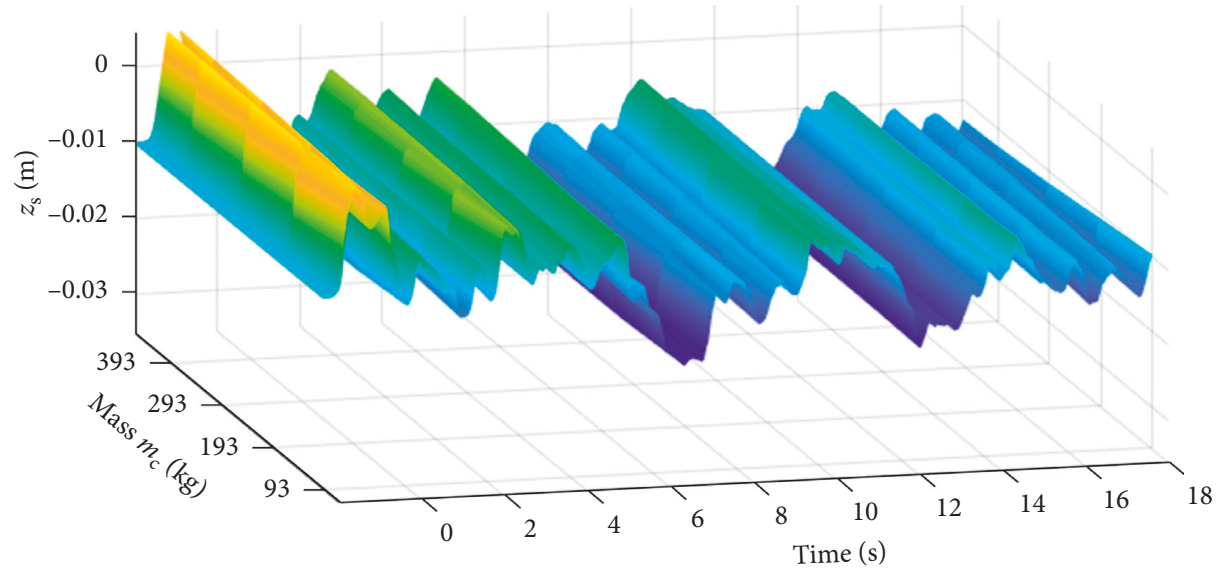

FIGURE 7: The variation of $z_{\mathrm{s}}$ by mass of the car $m_{\mathrm{s}}$ for same road profile and velocity of the car.

$E\left\{\mathbf{n}(t) \mathbf{n}(t)^{\prime}\right\}=R \delta\left(t-t^{\prime}\right)$, where $R$ is the positive defined matrix.

In general, the dynamic model of the suspension system taking into account the road excitation model and used for state estimation is described by

$$
\begin{aligned}
& \left\{\begin{array}{l}
\frac{d \underline{z}}{d t}=\mathbf{f}(\underline{z}(t))+\mathbf{g}(\underline{z}(t)) \mathbf{u}(t)+\mathbf{w}(t), \\
\underline{y}(t)=\mathbf{h}(\underline{z}(t))+\zeta(\underline{z}(t)) \mathbf{u}(t)+\mathbf{n}(t),
\end{array}\right. \\
& F_{\mathrm{d}}=c_{\mathrm{w}}\left(z_{5}-z_{3}\right)+d_{\mathrm{w}}\left(z_{6}-z_{4}\right) \text {. }
\end{aligned}
$$

In the static state, $u(t)=0$ and $v(t)=0$, and the system remains the natural characteristics $\mathbf{f}(\underline{z}(t))$ and $\mathbf{h}(\underline{z}(t))$. When $v(t) \neq 0$, the suspension system is effected by $\mathbf{g}(\underline{z}(t))$, $\zeta(\underline{z}(t))$, and road profile. The models (11) and (12) are used to design the state estimator, and this model is depicted in Figure 8.

\section{Estimation of the States of the Suspension System by Using the SPKF}

The SPKF known as one of the state estimation methods has some advantages better than EKF by application ranges, and this method estimates more accurately the states for the second-order system or higher; meanwhile, computational complexity is same as EKF. SPKF is easily implemented as there is no requirement of the Jacobi matrix calculation.

For the EKF, the system's nonlinear dynamic is linearized at the sampling time, the input distributions are mapped via the linearized dynamic function to calculate the output distributions, and the output distributions is less accurate if there is high nonlinear of the system dynamic.

For the SPKF, the whole of the input distributions (systems noise and load profile) are mapped thought the nonlinear dynamic functions to get the output distribution. Figure 9 explains the differences basically between the EKF and SPKF though the calculation of distribution of $x$ at the time $k$ based on the nonlinear function $\Phi(\cdot)$ and the distribution of $x$ at the time $k-1$. We can see that the distribution of $x(k)$ is calculated more accurately than by EKF [13-15].

For the suspension system, the distribution of the road excitation depends on the velocity of the car for the same road profile, so the function $\mathbf{g}(\underline{z}(t))$ in the dynamic model also depends on the variance $z_{\mathrm{r}}$; it is nonlinear. So that, applying the SPKF coming with the covariance matrices update by the velocity of the car could improve the accuracy of the state estimation as well as the road excitation $z_{\mathrm{r}}$.

Consider the time sampling to be small enough, the system (11) can be converted to the discrete model at the sampling time $k$ as 


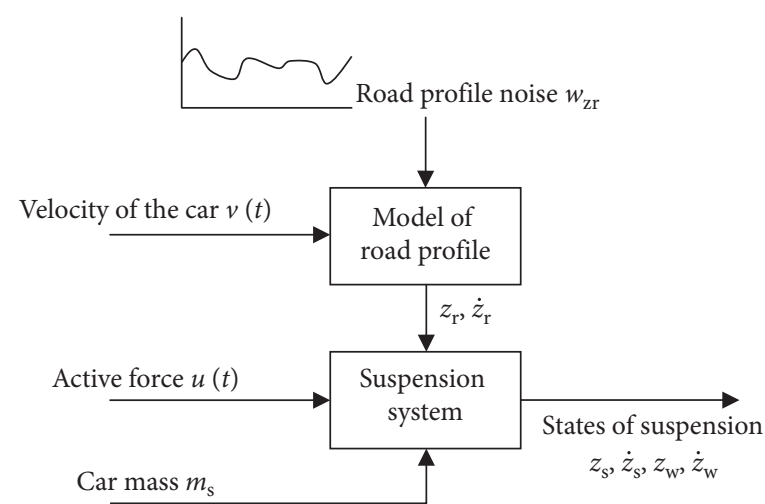

Figure 8: The model of the suspension systems taking into account the road profile and velocity of the car.

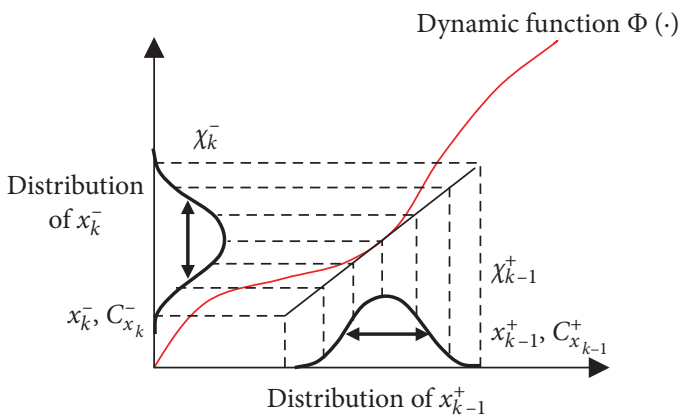

(a)

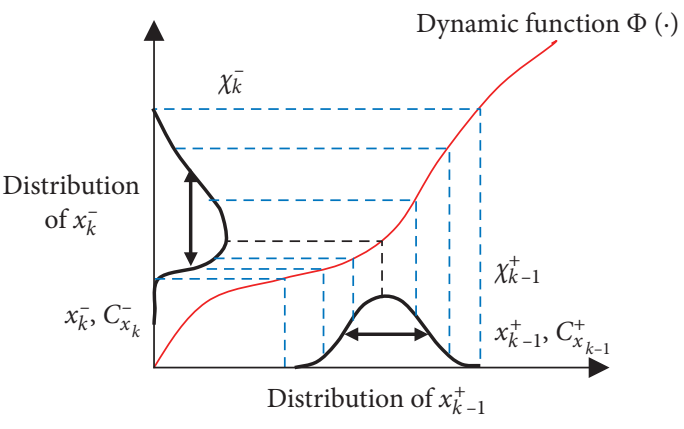

(b)

FIgURE 9: Explanation of the dynamic mapping to determine the distribution of the $x$ at the sampling time $k$ via the nonlinear function calculated by the distribution of $x$ at the sampling time $k-1$ for the (a) EKF and (b) SPKF.

$$
\left\{\begin{array}{l}
\underline{z}(k)=\mathbf{f}_{k-1}(\underline{z}(k-1))+\mathbf{g}_{k-1}(\underline{z}(k-1)) \mathbf{u}(k-1) \\
\quad+\mathbf{w}(k-1), \\
\underline{y}(k)=\mathbf{h}(\underline{z}(k))+\zeta(\underline{z}(k)) \mathbf{u}(k)+\mathbf{n}(k) .
\end{array}\right.
$$

Model (13) is used to estimate the suspension system states which include the position, velocities of the sprung and unsprung mass, and also the road excitation $z_{\mathrm{r}}$. The measured output is $y(k)$, including the accelerations and deflections of two masses. The velocity of the car also is the input of the SPKF. The road excitation for the same road profile $w_{\mathrm{zr}}$ has the covariance matrix depending on the velocity of the car.
The process of the state estimation $z_{\mathrm{s}}, \dot{z}_{\mathrm{s}}, z_{\mathrm{w}}, \dot{z}_{\mathrm{w}}, z_{\mathrm{r}}$ using SPKF at the sampling time $k$ is conducted by two main steps:

Step 1

(i) Forms the augmented state vector at the sampling time $k-1$ based on the estimated states at the previous time $k-1$ and the vector of mean values of the system noise $\bar{w}$ and measured noise $\bar{n}$. Note that vector $\bar{w}$ has the last element which is the mean of the road excitation acted by the velocity of the car, so those vectors are

$$
\begin{aligned}
& \bar{w}(v(k-1))=\left[\bar{w}_{\mathrm{zs}} \bar{w}_{\mathrm{dzs}} \bar{w}_{\mathrm{zw}} \bar{w}_{\mathrm{dzw}} \bar{w}_{\mathrm{zr}}(v(k-1)) \bar{w}_{\mathrm{dzr}}(v(k-1))\right]^{T}, \\
& \underline{\hat{z}}_{k-1}^{a,+}=\left[\left(\underline{\hat{z}}_{k-1}^{a,+}\right)^{T} \bar{w}(v(k-1)) \bar{n}\right]^{T} \text {. }
\end{aligned}
$$

(ii) Forms the estimated covariance matrix of the estimation error in the previous step including the covariance matrices of the estimation error, the noise error, and the measured error. The covariance matrix 
of system noise also depends on the velocity of the car:

$$
C_{\widetilde{z}, k-1}^{a,+}=\operatorname{diag}\left(C_{\widetilde{z}, k-1}^{+} C_{\widetilde{w}}(v(k-1)) C_{\widetilde{n}}\right) .
$$

(iii) The augmented sigma point matrix containing $p+1$ sigma points is established as

$$
\begin{aligned}
\chi_{k-1}^{a,+} & =\left[\underline{\hat{z}}_{k-1}^{a,+}, \underline{\hat{z}}_{k-1}^{a,+}+\lambda \sqrt{C_{\underline{\underline{z}}, k-1}^{a,+}}, \hat{\underline{z}}_{k-1}^{a,+}-\lambda \sqrt{C_{\underline{\underline{z}}, k-1}^{a,+}}\right] \\
& \triangleq\left[\begin{array}{lll}
\chi_{k-1}^{z,+} & \chi_{k-1}^{\mathrm{w},+} & \chi_{k-1}^{n,+}
\end{array}\right]^{T} .
\end{aligned}
$$

(iv) Calculates priori sigma points at the sampling time $k$ by using the suspension system dynamic (13) and the augmented sigma point matrix at the sampling time $k-1$. For the sigma point $i$, estimation of the priori sigma points is calculated by following equation:

$$
\begin{aligned}
i= & 1: p+1 \chi_{k, i}^{z,-}=\mathbf{f}_{k-1}\left(\chi_{k-1}^{a,+}\right)+\mathbf{g}_{k-1}\left(\chi_{k-1}^{a,+}\right) \mathbf{u}(k-1) \\
& +\chi_{k-1, i}^{w,+} .
\end{aligned}
$$

(v) The priori state estimation is calculated by using the priori sigma points mapped via the system dynamic $\chi_{k-1, i}^{a,-}$ as

$$
\begin{aligned}
\hat{\underline{z}}_{k}^{-} & \approx \sum_{i=0}^{p} \alpha_{i}^{(m)}\left(\mathbf{f}_{k-1}\left(\chi_{k-1, i}^{z,+}\right)+\mathbf{g}_{k-1}\left(\chi_{k-1, i}^{z,+}\right) \mathbf{u}(k-1)+\chi_{k-1, i}^{\mathrm{w},+}\right) \\
& =\sum_{i=0}^{p} \alpha_{i}^{(m)} \chi_{k, i}^{z,-} .
\end{aligned}
$$

(vi) The covariance matrix of the estimation errors is updated by the following equation:

$$
C_{\underline{z}, k}^{-}=\sum_{i=0}^{p} \alpha_{i}^{(c)}\left(\chi_{k, i}^{z,-}-\underline{\hat{z}}_{k}^{-}\right)\left(\chi_{k, i}^{z,-}-\underline{\hat{z}}_{k}^{-}\right)^{T} .
$$

Note that $\lambda$ is the scaling parameter; $\alpha_{i}^{(m)}$ and $\alpha_{i}^{(c)}$ are the weighted mean and covariance of $\chi$ which are chosen by unscented Kalman filter [16]. (vii) The estimated output distribution is calculated by using $\chi_{k, i}^{z,-}$ :

$$
i=1: p+1, \quad \psi_{k, i}=\mathbf{h}\left(\chi_{k, i}^{z,-}\right)+\zeta\left(\chi_{k, i}^{z,-}\right) \mathbf{u}(k)+\chi_{k-1, i}^{n,+}
$$

(i) The estimated output of the suspension system at the sampling time $k$ is estimated by following equation:

$$
\begin{aligned}
(k) \underline{\hat{y}} & \approx \sum_{i=0}^{p} \alpha_{i}^{(m)}\left(\mathbf{h}\left(\chi_{k, i}^{z,-}\right)+\zeta\left(\chi_{k, i}^{z,-}\right) \mathbf{u}(k)+\chi_{k-1, i}^{n,+}\right) \\
& =\sum_{i=0}^{p} \alpha_{i}^{(m)} \psi_{k, i} .
\end{aligned}
$$

Step 2

(i) Update the covariance matrices of the output errors at the sampling time $k$ and the output errors and state estimation errors; these matrices depend on the sigma points and matrix $\psi_{k, i}$ (calculated by equation (20)) and also $\underline{\hat{z}}_{k}^{-}, \underline{\hat{y}}(k)$ :

$$
\begin{aligned}
C_{\widetilde{y}, k} & =\sum_{i=0}^{p} \alpha_{i}^{(c)}\left(\psi_{k, i}-\underline{\hat{y}}(k)\right)\left(\psi_{k, i}-\underline{\hat{y}}(k)\right)^{T}, \\
C_{\widetilde{z} \widetilde{y}, k}^{-} & =\sum_{i=0}^{p} \alpha_{i}^{(c)}\left(\chi_{k, i}^{z,-}-\underline{\hat{z}}_{k}^{-}\right)\left(\psi_{k, i}-\underline{\hat{y}}(k)\right)^{T} .
\end{aligned}
$$

(ii) Calculate the estimation gain matrix as

$$
G_{k}=\frac{C_{\widetilde{z} \tilde{y}, k^{-}}}{C_{\widetilde{y}, k}}
$$

(iii) Update the priori estimation states calculated at the step 1 by taking into account the output errors by the following equation, we have the estimation state as

$$
\underline{\hat{z}}_{k}^{+}=\underline{\hat{z}}_{k}^{-}+G_{k}(\underline{y}(k)-\underline{\hat{y}}(k))
$$

(iv) Estimate the dynamic wheel load:

$$
\widehat{F}_{\mathrm{d} k}^{+}=c_{\mathrm{w}}\left(\widehat{z}_{5 k}^{+}-\widehat{z}_{3 k}^{+}\right)+d_{\mathrm{w}}\left(\widehat{z}_{6 k}^{+}-\widehat{z}_{4 k}^{+}\right) .
$$

(v) Update the covariance matrix of the estimation errors: 


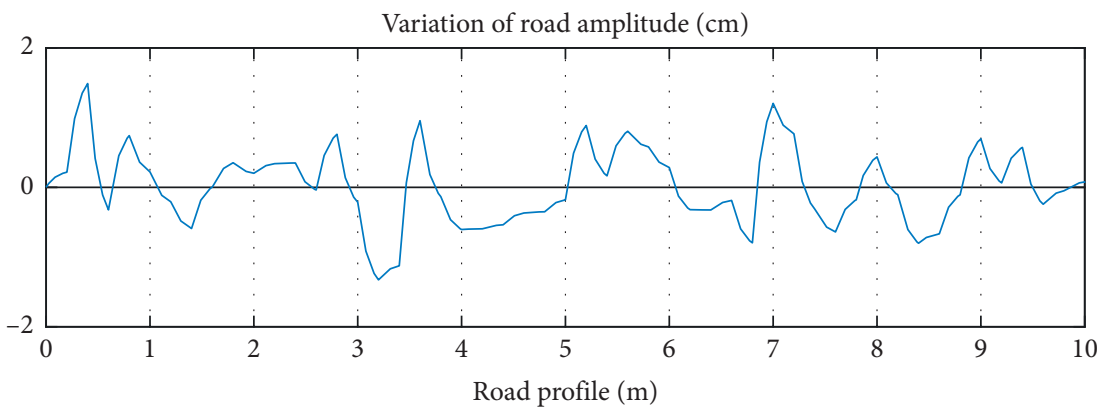

FIgURE 10: Road profile with length $1000 \mathrm{~m}$, sampled $10 \mathrm{~cm}$ per measured point. Road profile PDF: $\min =-2.319 \mathrm{~cm}$; $\max =2.348 \mathrm{~cm}$; mean $=0.0131 \mathrm{~cm}$; median $=0.013 \mathrm{~cm}$; variance $=0.331678 \mathrm{~cm}$.

$$
C_{\underline{\underline{z}}, k}^{+}=C_{\underline{\widetilde{z}}, k}^{-}-G_{k} C_{\widetilde{\underline{y}}, k} G_{k}^{T} .
$$

(vi) Back to the step 1 for the next sampling time $k+1$.

The vector of process noise means and the covariance matrix of the process noise errors depend on the velocity of the car for the same road profile. At each sampling time, these matrices need to be updated by the velocity of the car and road profile. For the particular road profile, the practical examinations need to be done to determine the covariance matrix of the process noise errors with respect to the velocity of the car.

\section{State Estimation Results of the Suspension System}

The physical parameters of the suspension system are

$$
\begin{aligned}
\lambda & =0.2, \\
c_{c} & =8399(\mathrm{~N} / \mathrm{m}), \\
c_{\mathrm{w}} & =151176(\mathrm{~N} / \mathrm{m}), \\
d_{c} & =665(\mathrm{~N} \mathrm{sec} / \mathrm{m}), \\
d_{\mathrm{w}} & =50(\mathrm{~N} \mathrm{sec} / \mathrm{m}), \\
m_{c} & =94.2(\mathrm{~kg}), \\
m_{\mathrm{w}} & =22.9(\mathrm{~kg}) .
\end{aligned}
$$

Figure 10 shows the road profile (length $1000 \mathrm{~m}$, sampled $10 \mathrm{~cm} /$ point), and the distribution characteristics of the road profile are depicted in Figure 11 and Table 1.

The covariance matrices depending on the velocity of the car are valued as

$$
\begin{aligned}
C_{\widetilde{w}}(v=5 \mathrm{~km} / \mathrm{h}) & =\left[\begin{array}{cccccc}
1.85 & 0 & 0 & 0 & 0 & 0 \\
0 & 0.175 & 0 & 0 & 0 & 0 \\
0 & 0 & 0.85 & 0 & 0 & 0 \\
0 & 0 & 0 & 0.125 & 0 & 0 \\
0 & 0 & 0 & 0 & 3.01 & 0 \\
0 & 0 & 0 & 0 & 0 & 0.001
\end{array}\right], \\
C_{\widetilde{w}}(v=20 \mathrm{~km} / \mathrm{h}) & =\left[\begin{array}{ccccccc}
0.7 & 0 & 0 & 0 & 0 & 0 \\
0 & 0.2 & 0 & 0 & 0 & 0 \\
0 & 0 & 0.7 & 0 & 0 & 0 \\
0 & 0 & 0 & 0.2 & 0 & 0 \\
0 & 0 & 0 & 0 & 0.7 & 0 & \\
0 & 0 & 0 & 0 & 0 & 0.012
\end{array}\right], \\
C_{\widetilde{w}}(v=40 \mathrm{~km} / \mathrm{h}) & =\left[\begin{array}{cccccc}
0.85 & 0 & 0 & 0 & 0 & 0 \\
0 & 0.175 & 0 & 0 & 0 & 0 \\
0 & 0 & 0.85 & 0 & 0 & 0 \\
0 & 0 & 0 & 0.35 & 0 & 0 \\
0 & 0 & 0 & 0 & 0.6 & 0 \\
0 & 0 & 0 & 0 & 0 & 0.01
\end{array}\right], \\
C_{\widetilde{w}}(v=60 \mathrm{~km} / \mathrm{h}) & =\left[\begin{array}{cccccc}
0.85 & 0 & 0 & 0 & 0 & 0 \\
0 & 0.175 & 0 & 0 & 0 & 0 \\
0 & 0 & 0.85 & 0 & 0 & 0 \\
0 & 0 & 0 & 0.35 & 0 & 0 \\
0 & 0 & 0 & 0 & 0.35 & 0 \\
0 & 0 & 0 & 0 & 0 & 0.002
\end{array}\right],
\end{aligned}
$$




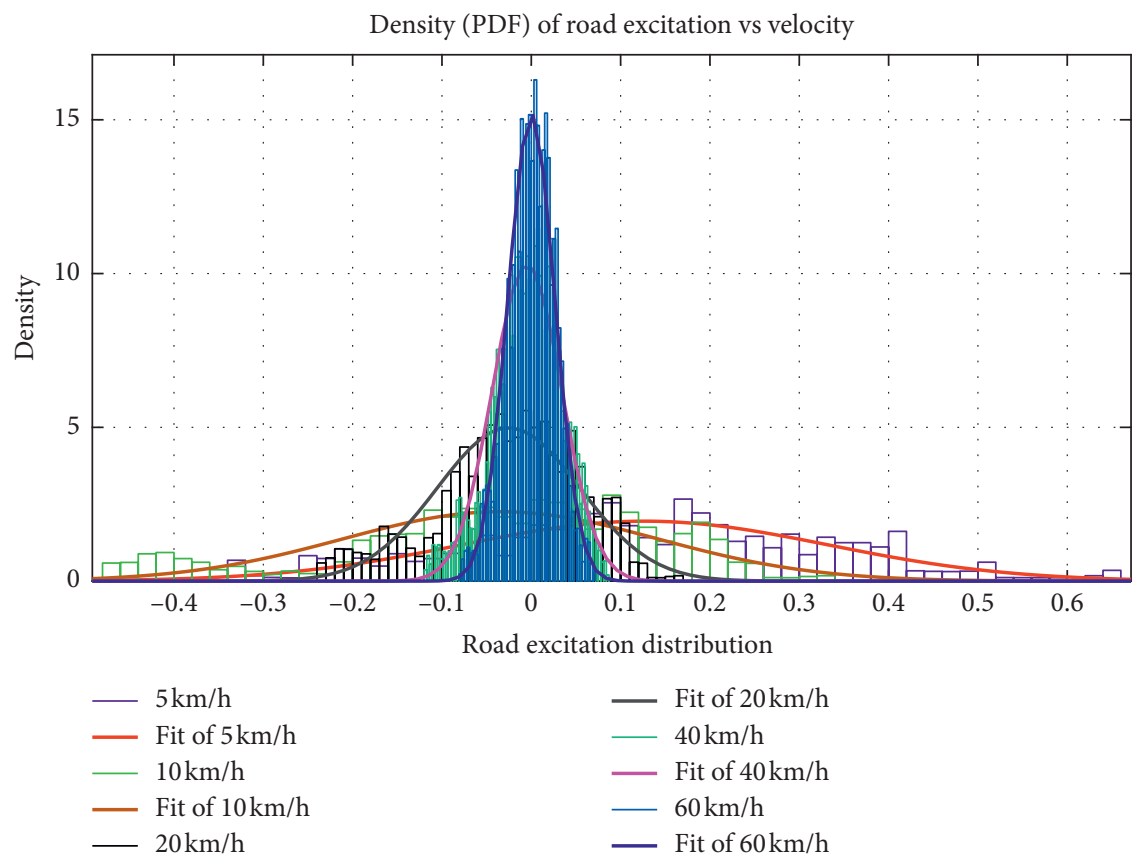

FIgURE 11: The distribution characteristics DPF of $z_{\mathrm{r}}$ by velocity of the car.

TABLE 1: The variation of the road distribution parameters $z_{\mathrm{r}}$ by the velocity of the car for the road profile shown in Figure 10 .

\begin{tabular}{|c|c|c|c|c|c|}
\hline & $v=5 \mathrm{~km} / \mathrm{h}$ & $v=10 \mathrm{~km} / \mathrm{h}$ & $v=20 \mathrm{~km} / \mathrm{h}$ & $v=40 \mathrm{~km} / \mathrm{h}$ & $v=60 \mathrm{~km} / \mathrm{h}$ \\
\hline $\operatorname{mean}\left(z_{\mathrm{r}}\right)(\mathrm{m})$ & 0.127 & -0.0346366 & -0.0254131 & -0.00482362 & $4.77238 e-05$ \\
\hline $\operatorname{variance}\left(z_{\mathrm{r}}\right)(\mathrm{m})$ & 0.0418896 & 0.031236 & 0.00639788 & 0.0015011 & 0.000690728 \\
\hline$\mu\left(z_{\mathrm{r}}\right)(\mathrm{m})$ & 0.127002 & -0.0346366 & -0.0254131 & -0.00482362 & $4.77238 e-05$ \\
\hline$\sigma\left(z_{r}\right)(\mathrm{m})$ & 0.20467 & 0.176737 & 0.0799867 & 0.038744 & 0.0262817 \\
\hline
\end{tabular}

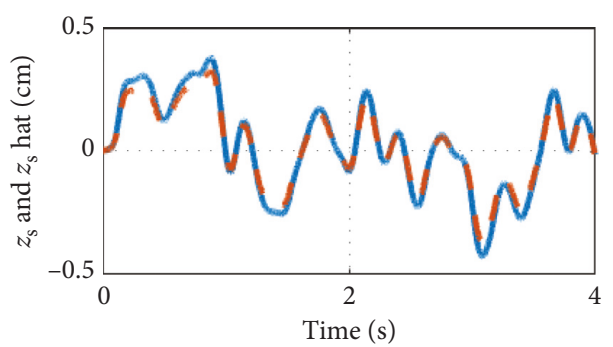

(a)

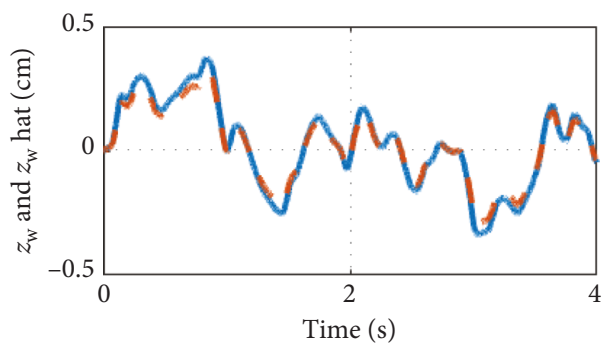

(c)

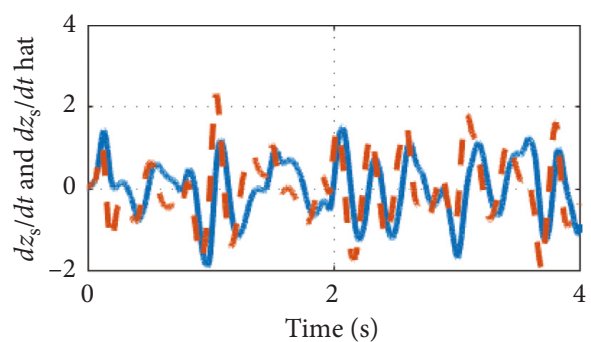

(b)

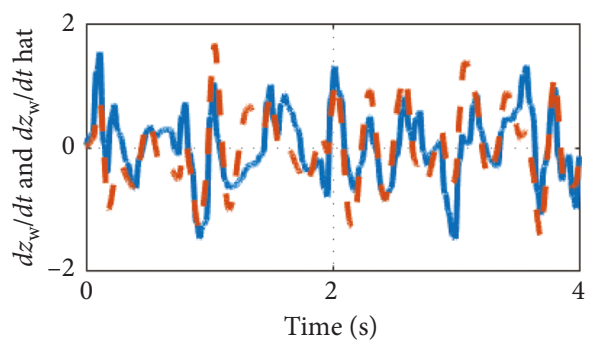

(d)

FIGURE 12: Continued. 


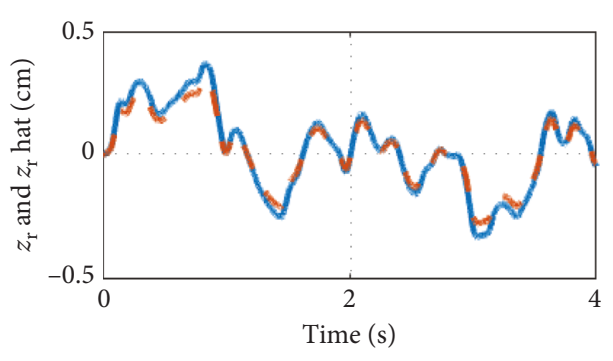

(e)

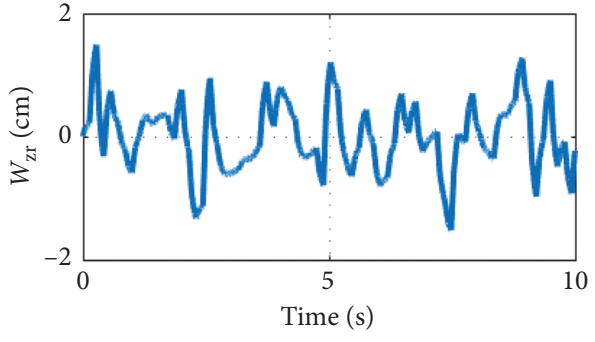

(f)

Figure 12: The real states (solid line) and estimated states using SPKF (dotted line) in the case of $5 \mathrm{~km} / \mathrm{h}$. (a) $z_{\mathrm{s}}$ and $z_{\mathrm{s}}$ hat. (b) $d z_{\mathrm{s}} / d t$ and $d z_{\mathrm{s}} /$ $d t$ hat. (c) $z_{\mathrm{w}}$ and $z_{\mathrm{w}}$ hat. (d) $d z_{\mathrm{w}} / d t$ and $d z_{\mathrm{w}} / d t$ hat. (e) $z_{\mathrm{r}}$ and $z_{\mathrm{r}}$ hat. (f) $w_{\mathrm{zr}}$.

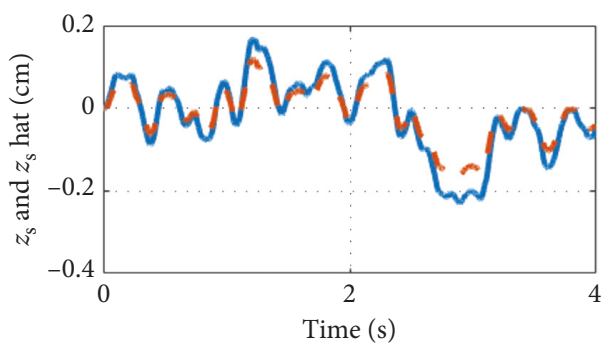

(a)

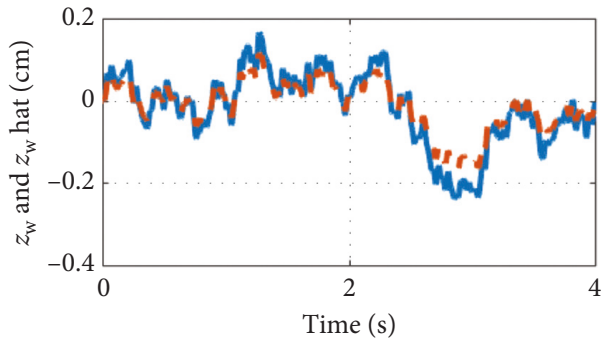

(c)

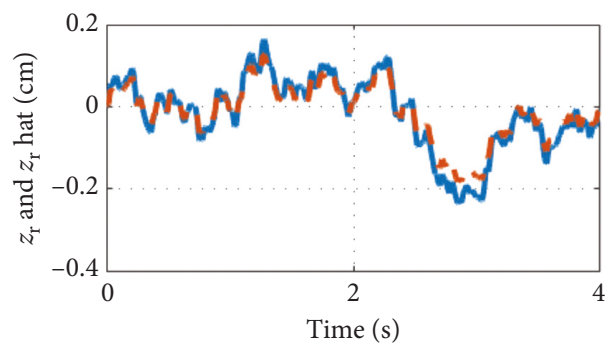

(e)

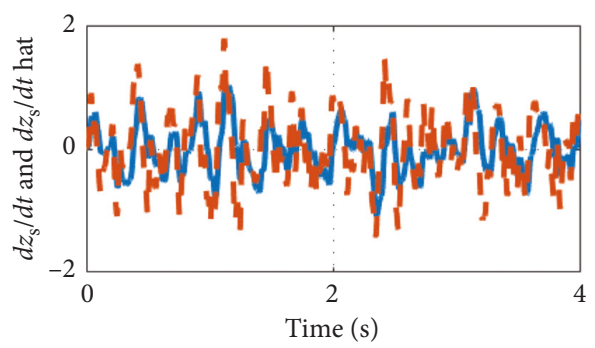

(b)

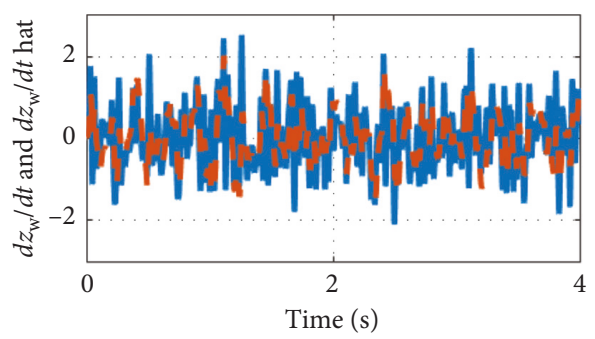

(d)

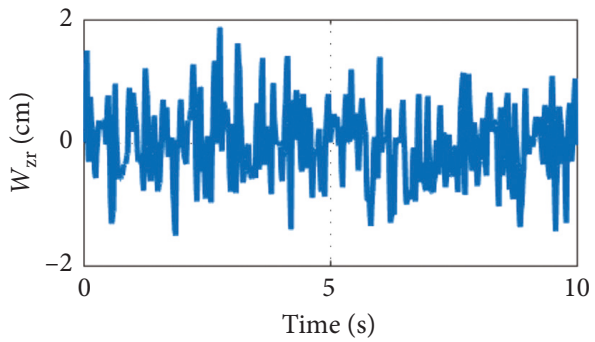

(f)

FIGURE 13: The real states (solid line) and estimated states using SPKF (dotted line) in the case of $20 \mathrm{~km} / \mathrm{h}$. (a) $z_{\mathrm{s}}$ and $z_{\mathrm{s}}$ hat. (b) $d z_{\mathrm{s}} / d t$ and $d z_{\mathrm{s}} /$ $d t$ hat. (c) $z_{\mathrm{w}}$ and $z_{\mathrm{w}}$ hat. (d) $d z_{\mathrm{w}} / d t$ and $d z_{\mathrm{w}} / d t$ hat. (e) $z_{\mathrm{r}}$ and $z_{\mathrm{r}}$ hat. (f) $w_{\mathrm{zr}}$.

The estimated states $\widehat{z}_{\mathrm{s}}, \dot{\vec{z}}_{\mathrm{s}}, \widehat{z}_{\mathrm{w}}, \dot{\bar{z}}_{\mathrm{w}}, \widehat{z}_{\mathrm{r}}$ by using the SPKF for the suspension system are depicted in Figure 12 to 16 for the velocities of the car $5 \mathrm{~km} / \mathrm{h}, 20 \mathrm{~km} / \mathrm{h}, 40 \mathrm{~km} / \mathrm{h}, 60 \mathrm{~km} / \mathrm{h}$, and $80 \mathrm{~km} / \mathrm{h}$. The errors of the state estimation errors are shown in Figure 17. Distribution of the state estimation errors is shown in Figure 18.

From the state estimation results and the distribution of the state estimation errors, we see the following.
For the estimation of $z_{\mathrm{s}}$ and $z_{\mathrm{w}}$, the distributions $z_{\mathrm{s}}-\widehat{z}_{\mathrm{s}}$ and $z_{w}-\widehat{z}_{w}$ are quite the same; the variance of the distributions is gradually reduced from $0.04 \mathrm{~cm}$ to $0.005 \mathrm{~cm}$ by the increasing of the velocity of the car from $5 \mathrm{~km} / \mathrm{h}$ to $80 \mathrm{~km} / \mathrm{h}$, respectively.

The distribution of $z_{\mathrm{r}}-\widehat{z}_{\mathrm{r}}$ is larger than the distributions of $z_{\mathrm{s}}-\widehat{z}_{\mathrm{s}}$ and $z_{w}-\widehat{z}_{w}$, the distribution of the estimation error $\widetilde{z}_{\mathrm{r}}=z_{\mathrm{r}}-\widehat{z}_{\mathrm{r}}$ is $0.25 \mathrm{~cm}$ when the velocity of the car 


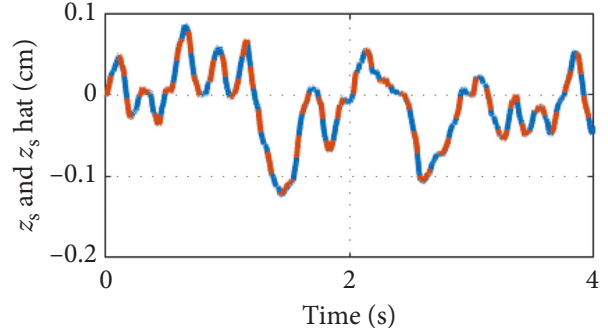

(a)

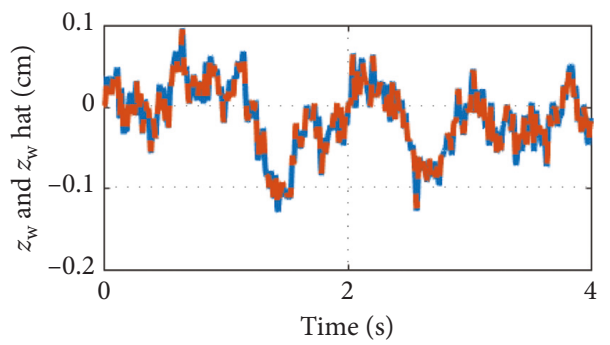

(c)

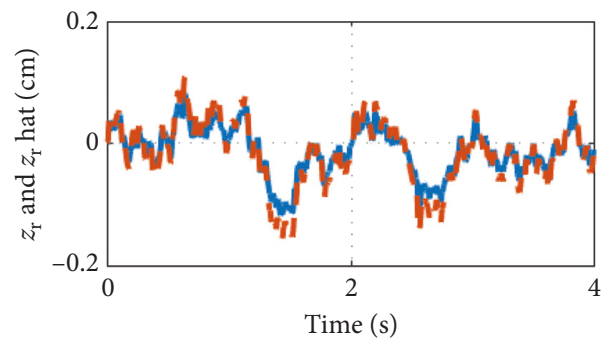

(e)

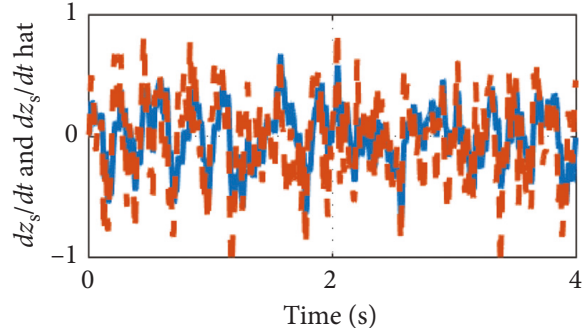

(b)

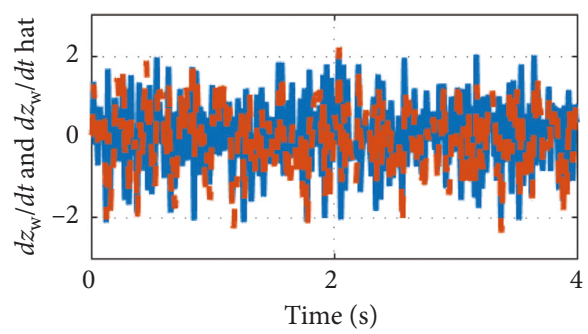

(d)

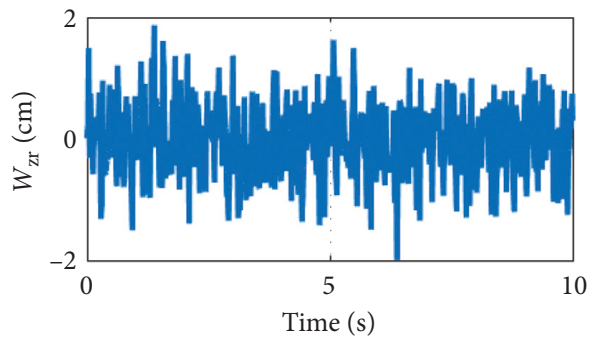

(f)

FIGURE 14: The real states (solid line) and estimated states using SPKF (dotted line) in the case of $40 \mathrm{~km} / \mathrm{h}$. (a) $z_{\mathrm{s}}$ and $z_{\mathrm{s}}$ hat. (b) $d z_{\mathrm{s}} / d t$ and $d z_{\mathrm{s}} /$ $d t$ hat. (c) $z_{\mathrm{w}}$ and $z_{\mathrm{w}}$ hat. (d) $d z_{\mathrm{w}} / d t$ and $d z_{\mathrm{w}} / d t$ hat. (e) $z_{\mathrm{r}}$ and $z_{\mathrm{r}}$ hat. (f) $w_{\mathrm{zr}}$.

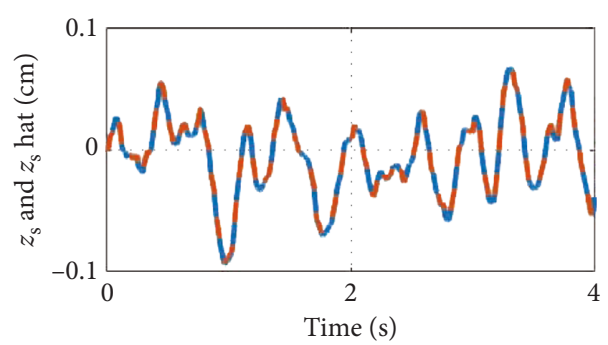

(a)

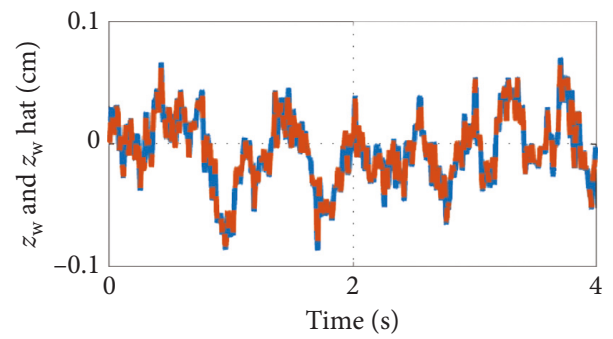

(c)

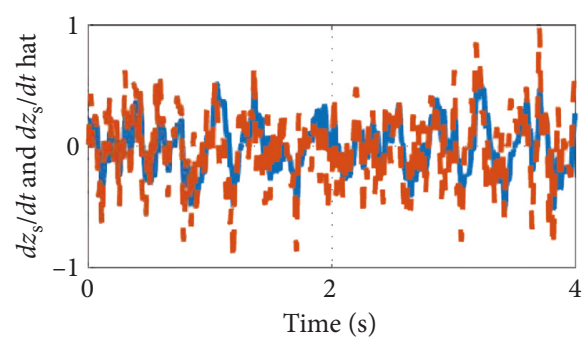

(b)

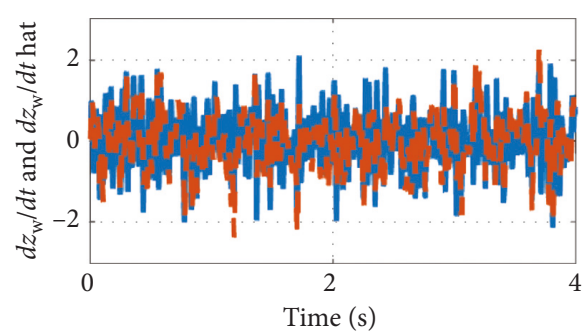

(d)

Figure 15: Continued. 


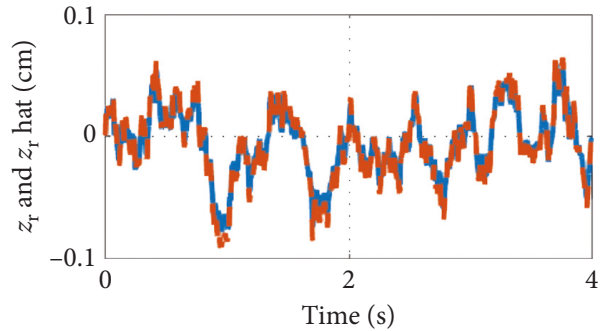

(e)

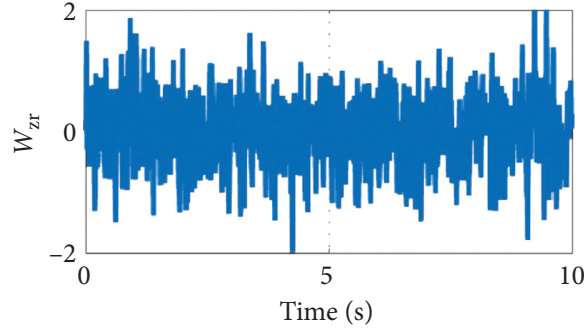

(f)

Figure 15: The real states (solid line) and estimated states using SPKF (dotted line) in the case of $60 \mathrm{~km} / \mathrm{h}$. (a) $z_{\mathrm{s}}$ and $z_{\mathrm{s}}$ hat. (b) $d z_{\mathrm{s}} / d t$ and $d z_{\mathrm{s}} /$ $d t$ hat. (c) $z_{\mathrm{w}}$ and $z_{\mathrm{w}}$ hat. (d) $d z_{\mathrm{w}} / d t$ and $d z_{\mathrm{w}} / d t$ hat. (e) $z_{\mathrm{r}}$ and $z_{\mathrm{r}}$ hat. (f) $w_{\mathrm{zr}}$.

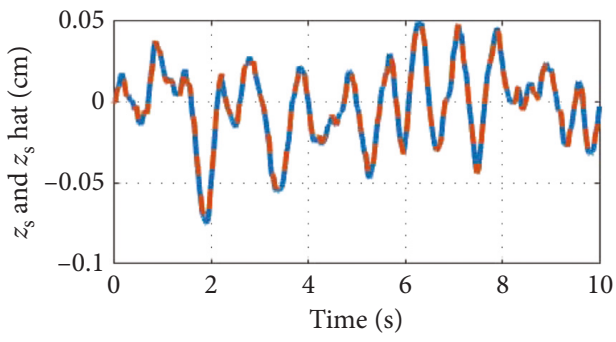

(a)

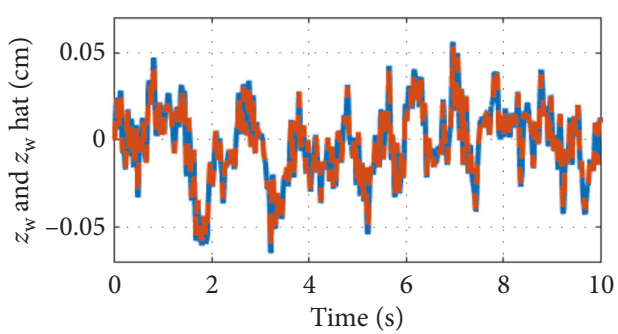

(c)

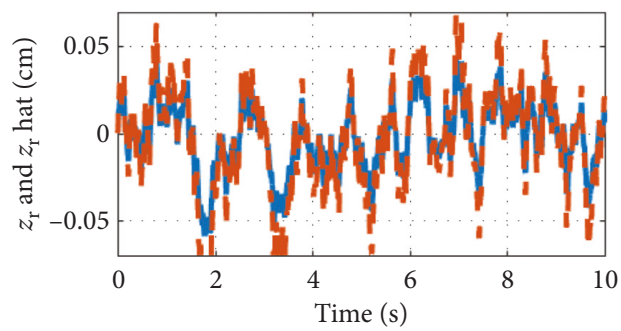

(e)

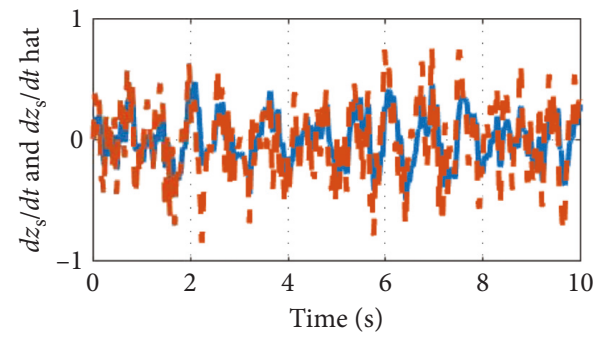

(b)

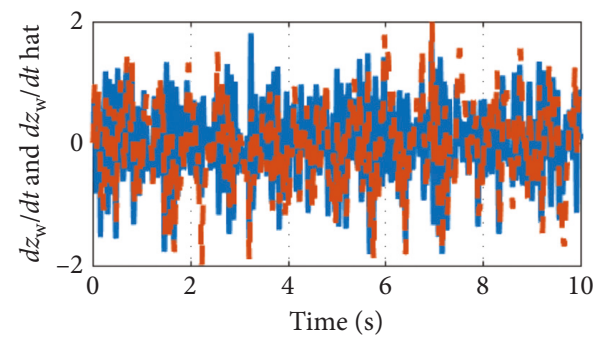

(d)

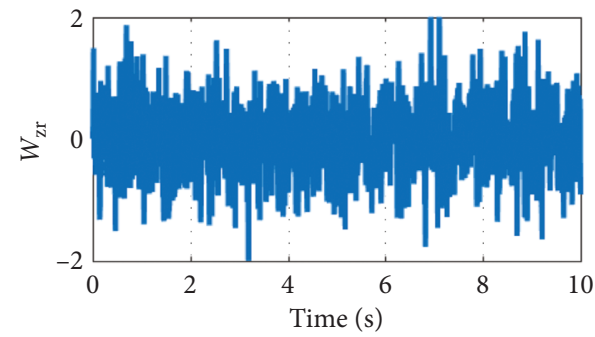

(f)

FIGURE 16: The real states (solid line) and estimated states using SPKF (dotted line) in the case of $80 \mathrm{~km} / \mathrm{h}$. (a) $z_{\mathrm{s}}$ and $z_{\mathrm{s}}$ hat. (b) $d z_{\mathrm{s}} / d t$ and $d z_{s} /$ $d t$ hat. (c) $z_{\mathrm{w}}$ and $z_{\mathrm{w}}$ hat. (d) $d z_{\mathrm{w}} / d t$ and $d z_{\mathrm{w}} / d t$ hat. (e) $z_{\mathrm{r}}$ and $z_{\mathrm{r}}$ hat. (f) $w_{\mathrm{zr}}$.

reaches $5 \mathrm{~km} / \mathrm{h}$, and $\widetilde{z}_{\mathrm{r}}$ decreases to $0.015 \mathrm{~cm}$ when the velocity of the car reaches $80 \mathrm{~km} / \mathrm{h}$.

For estimation of the velocity of two masses, the distribution of $d z_{\mathrm{s}} / d t-d \widehat{z}_{\mathrm{s}} / d t$ has variance $1 \mathrm{~cm} / \mathrm{s}$ for velocity of the car $5 \mathrm{~km} / \mathrm{h}$ and $0.1 \mathrm{~cm} / \mathrm{s}$ for the $80 \mathrm{~km} / \mathrm{h}$.

The distribution of $d z_{\mathrm{w}} / d t-d \widehat{z}_{\mathrm{w}} / d t$ has the variance larger more than two times in comparison with the distribution of $d z_{s} / d t-d \widehat{z}_{s} / d t$.

Figure 19 shows the estimated wheel dynamic load for the velocities of the car from $5 \mathrm{~km} / \mathrm{h}$ to $80 \mathrm{~km} / \mathrm{h}$.
Figure 20 presents the estimated states for the case of varying the mass of the sprung as $m_{\mathrm{s}}=94.3 \mathrm{~kg}$, $124.3 \mathrm{~kg}$, and $154.3 \mathrm{~kg}$, respectively.

\section{Conclusions}

This paper presents the method using SPKF to estimate the suspension system's states including the road excitation, the deflections, and the velocities of the sprung mass and unsprung mass. To estimate the states, we use the 


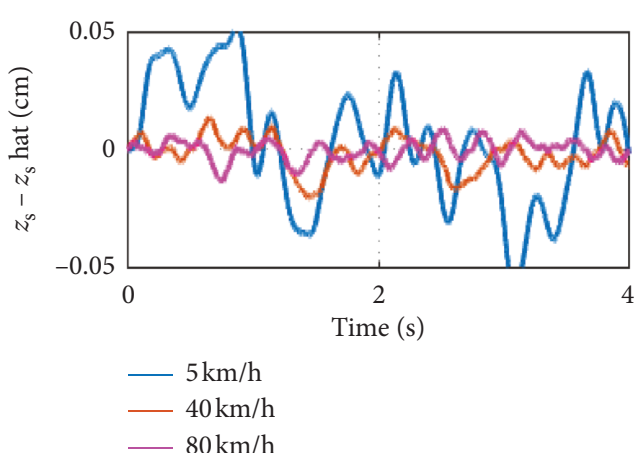

(a)

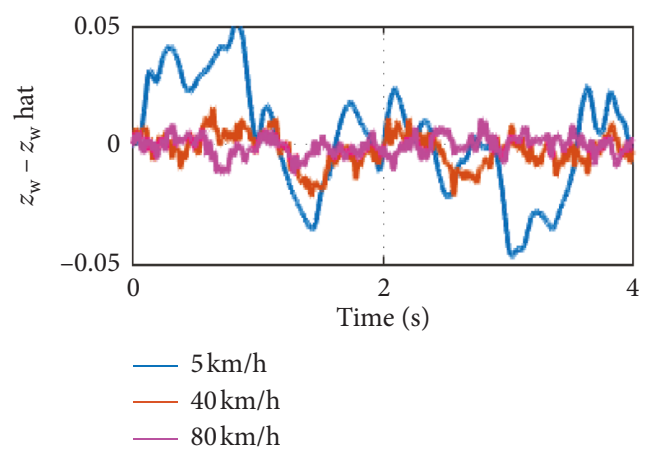

(c)

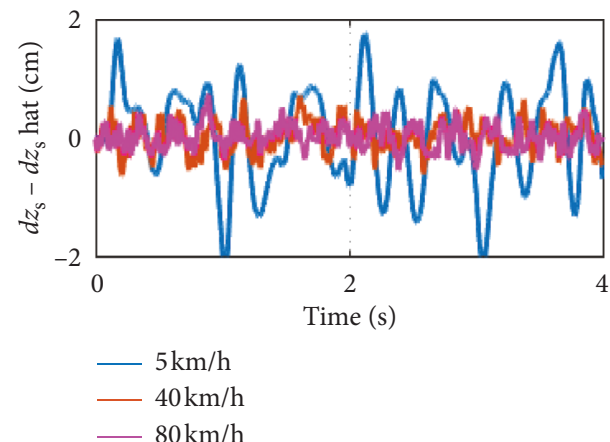

(b)

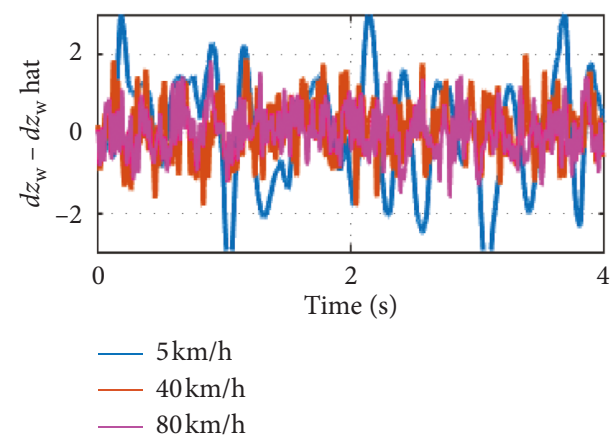

(d)

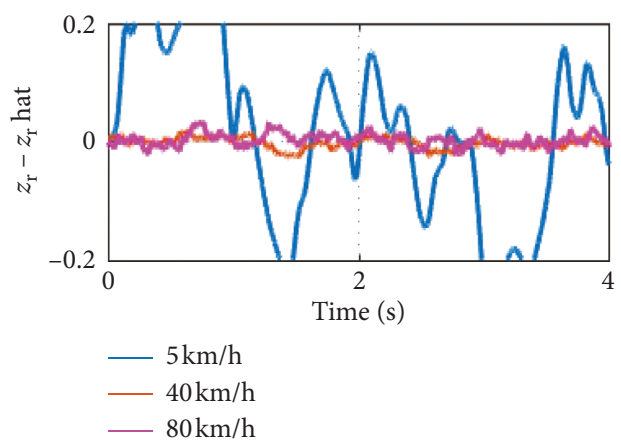

(e)

FIGURE 17: The state estimation errors by the velocities of the car. (a) $z_{\mathrm{s}}-z_{\mathrm{s}}$ hat. (b) $d z_{\mathrm{s}}-d z_{\mathrm{s}}$ hat. (c) $z_{\mathrm{w}}-z_{\mathrm{w}}$ hat. (d) $d z_{\mathrm{w}}-d z_{\mathrm{w}}$ hat. (e) $z_{\mathrm{r}}-z_{\mathrm{r}}$ hat.

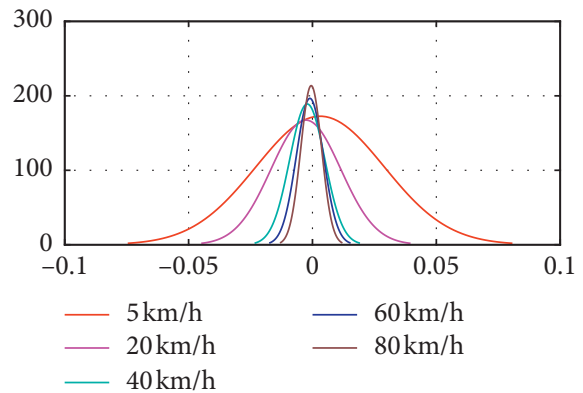

(a)

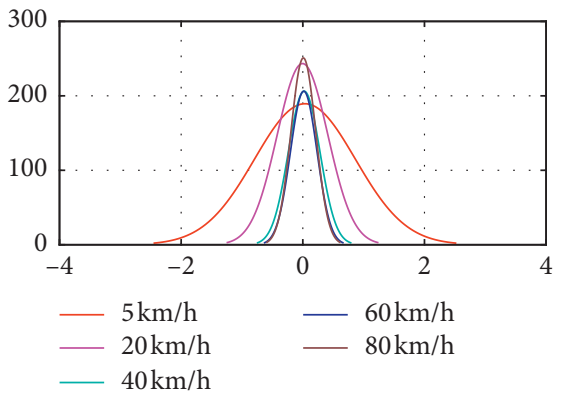

(b)

Figure 18: Continued. 


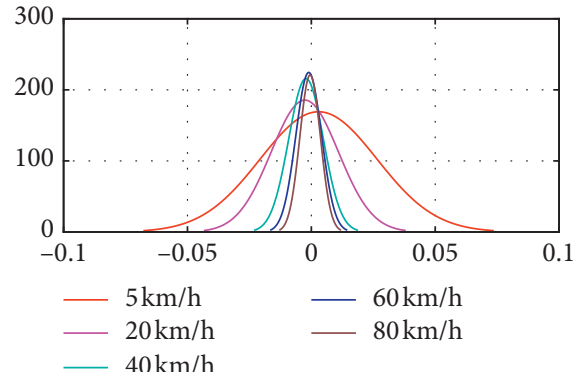

(c)

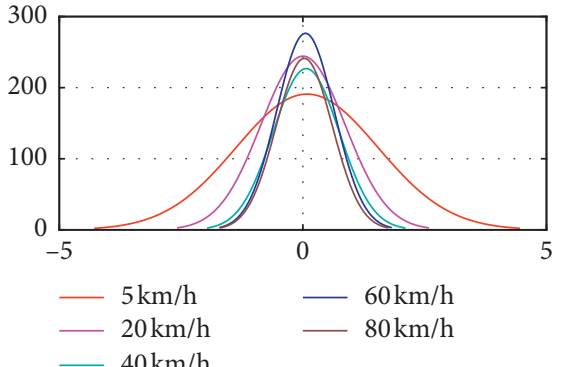

(d)

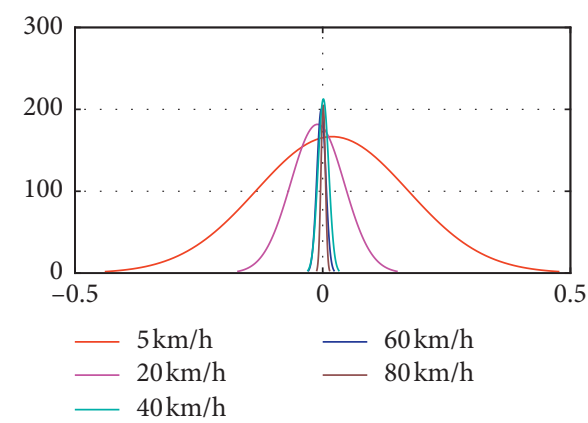

(e)

Figure 18: Distribution of the state estimation errors. (a) $z_{\mathrm{s}}-z_{\mathrm{s}}$ hat. (b) $d z_{\mathrm{s}}-d z_{\mathrm{s}}$ hat. (c) $z_{\mathrm{w}}-z_{\mathrm{w}}$ hat. (d) $d z_{\mathrm{w}}-d z_{\mathrm{w}}$ hat. (e) $z_{\mathrm{r}}-z_{\mathrm{r}}$ hat.

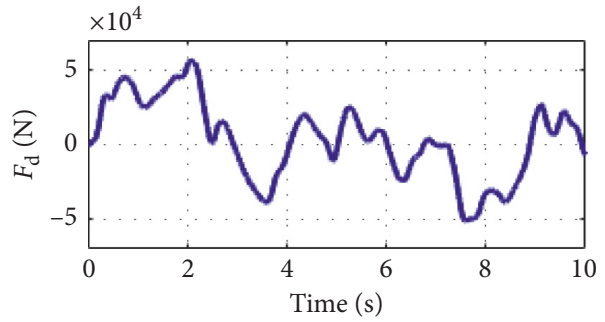

(a)

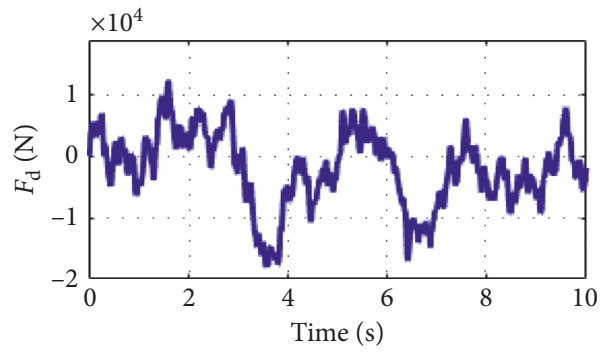

(c)

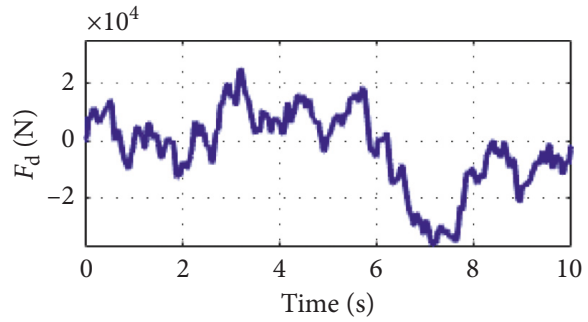

(b)

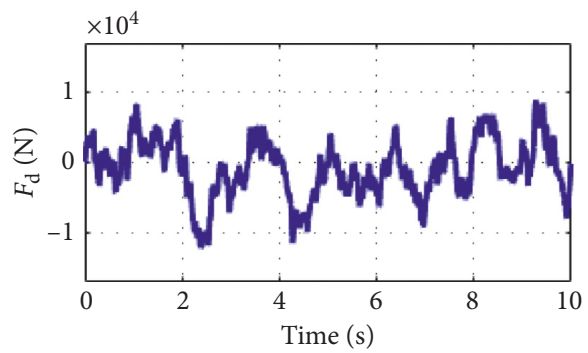

(d)

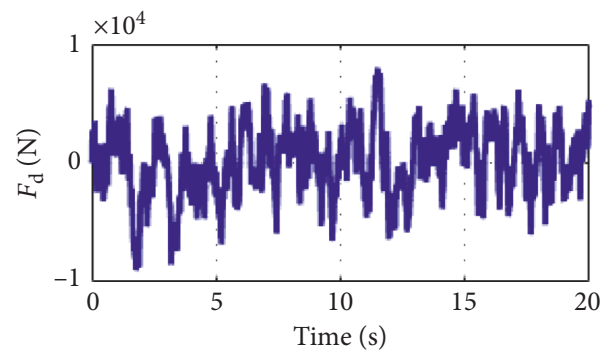

(e)

Figure 19: The $F_{\mathrm{d}}$ estimation versus the velocity of the car. (a) $5 \mathrm{~km} / \mathrm{h}$. (b) $20 \mathrm{~km} / \mathrm{h}$. (c) $40 \mathrm{~km} / \mathrm{h}$. (d) $60 \mathrm{~km} / \mathrm{h}$. (e) $80 \mathrm{~km} / \mathrm{h}$. 


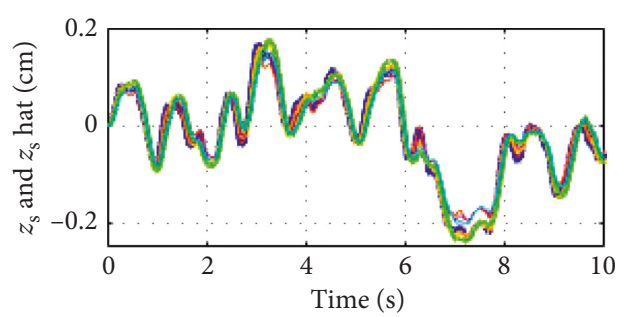

(a)

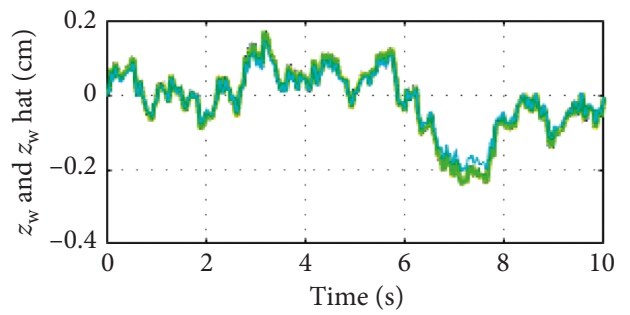

(c)

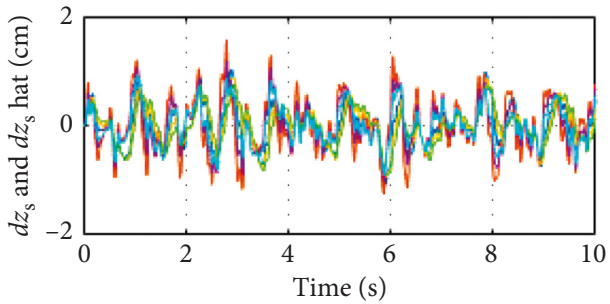

(b)

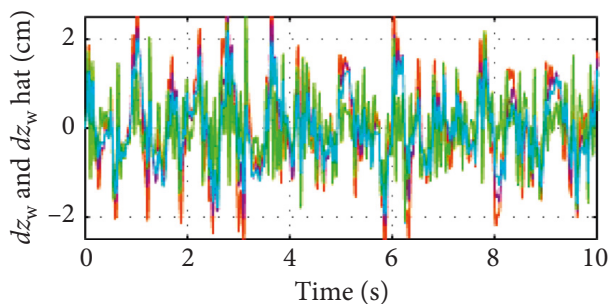

(d)

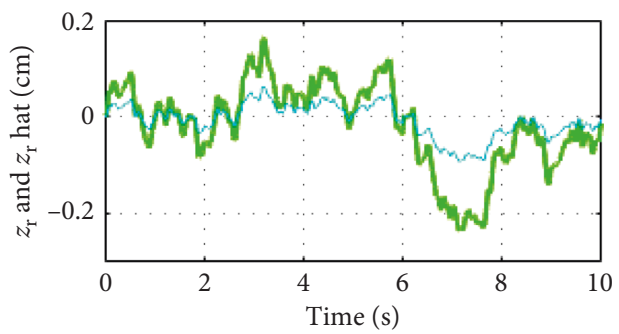

(e)

Figure 20: The estimated states for the case of varying the mass of the sprung. Case $1: m_{\mathrm{s}}=94.38 \mathrm{~kg}$, blue solid line for suspension system states and red solid line for estimated states. Case 2: $m_{\mathrm{s}}=124.3 \mathrm{~kg}$, orange solid line for suspension system states and purple solid line for estimated states. Case 3: $m_{\mathrm{s}}=154.3 \mathrm{~kg}$, green solid line for suspension system states and light blue solid line for estimated states. (a) $z_{\mathrm{s}}$ and $z_{\mathrm{s}}$ hat. (b) $d z_{\mathrm{s}} / d t$ and $d z_{\mathrm{s}} / d t$ hat. (c) $z_{\mathrm{w}}$ and $z_{\mathrm{w}}$ hat. (d) $d z_{\mathrm{w}} / d t$ and $d z_{\mathrm{w}} / d t$ hat. (e) $z_{\mathrm{r}}$ and $z_{\mathrm{r}}$ hat.

covariance matrices of the estimation errors varying by the velocity of the car. By taking advantage of this, the states of the system are estimated better, especially the road excitation. The mathematical model of the suspension system is rewritten for the state estimation problem; the stochastic load profile is supposed the main noise input. The stochastic of the road excitation depending on the car's velocity is considered in the model. The estimated results calculated based on the practical road profile data with some particular velocities of the car show that the state estimation errors are getting smaller when the velocity of the car is higher; the suspension system's states are estimated quite accurately in comparison with the real states. State estimation of the suspension system taking into account the road excitation depending on the velocity of the car based on the SPKF is the main contribution of this paper.

\section{Data Availability}

The practical data of the road profile used to support the findings of this study have been collected, measured, and processed by the research group under under grant no. B2016-TNA-06. The road profile data used to support the findings of this study are available from the corresponding author upon request.

\section{Conflicts of Interest}

The authors declare that they have no conflicts of interest.

\section{Acknowledgments}

This research was funded by the Vietnam Ministry of Education and Training under grant no. B2016-TNA-06.

\section{References}

[1] S. Chen, D. Wang, A. Zuo, Z. Chen, W. Li, and J Zan, "Vehicle ride comfort analysis and optimization using design of experiment," in Proceedings of the Second International Conference on Intelligent Human-Machine Systems and Cybernetics, Nanjing, China, August 2010.

[2] P. E. Uys, P. S. Els, and M. Thoresson, "Suspension settings for optimal ride comfort of off-road vehicles travelling on roads with different roughness and speeds," Journal of Terramechanics, vol. 44, no. 2, pp. 163-175, 2007.

[3] A. Turnip, I. R. Setiawan, M. Faizal Amri, and T. A. Tamba, "Controller design for active suspension system based on skyhook reference model," in Proceedings of the International 
Conference on Technology, Informatics, Management, Engineering \& Environment (TIME-E), North Sumatra, Indonesia, September 2015.

[4] J. Lin and R.-J. Lian, "Intelligent control of active suspension systems," IEEE Transactions on Industrial Electronics, vol. 58, no. 2, pp. 618-628, 2011.

[5] Z. Wang, M. Dong, Y. Qin, Y. Du, F. Zhao, and L. Gu, "Suspension system state estimation using adaptive Kalman filtering based on road classification," Vehicle System Dynamics, vol. 55, no. 3, pp. 371-398, 2017.

[6] S.-S. Yim, J.-H. Seok, and J.-J. Lee, "State estimation of the nonlinear suspension system based on nonlinear Kalman filter," in Proceedings of the 12th International Conference on Control, Automation and Systems, Jeju Island, South Korea, October 2012.

[7] R. C. Baker and B. Charlie, "Improved unscented Kalman filter for bounded state estimation," in Proceedings of the Electronics, Communications and Control (ICECC), pp. 2101-2104, Ningbo, China, September 2011.

[8] K. Rajeswari and Anjali, "Extended Kalman filter for vehicle suspension system," Applied Mechanics and Materials, vol. 573 , pp. $317-321,2014$.

[9] G. Koch, T. Kloiber, E. Pellegrini, and B. Lohmann, “A nonlinear estimator concept for active vehicle suspension control," in Proceeding of the 2010 American Control Conference, pp. 4576-4581, Baltimore, MD, USA, June 2010.

[10] D. Hrovat, "Survey of advanced suspension developments and related optimal control applications," Automatica, vol. 33, no. 10, pp. 1781-1817, 1997.

[11] Y. Qin, R. Langari, Z. Wang, C. Xiang, and M. Dong, "Road profile estimation for semi-active suspension using an adaptive kalman filter and an adaptive super-twisting observer," in Proceeding of the 2017 American Control Conference (ACC), pp. 973-978, Seattle, WA, USA, May 2017.

[12] F. Yu, J.-W. Zhang, and D. A. Crolla, "A study of a Kalman filter active vehicle suspension system using correlation of front and rear wheel road inputs," Proceedings of the Institution of Mechanical Engineers, Part D: Journal of Automobile Engineering, vol. 214, no. 5, pp. 493-502, 2000.

[13] B. Ritter, E. Mora, T. Schlicht, A. Schild, and U. Konigorski, "Adaptive sigma-point Kalman filtering for wind turbine state and process noise estimation," Journal of Physics: Conference Series, vol. 1037, Article ID 032003.

[14] Rudolph van der Merwe \& EWan, Sigma-Point Kalman Filters for Probabilistic Inference in Dynamic State-Space Models, OGI School of Science \& Engineering Oregon, Health \& Science University, Beaverton, OR, USA, 2004.

[15] L. P. Gregory, "Sigma-point Kalman filtering for battery management systems of LiPB-based HEV battery packs: part 1: introduction and state estimation," Journal of Power Sources, vol. 161, no. 2, pp. 1356-1368, 2006.

[16] S. Papp, K. György, A. Kelemen, and L. Jakab-Farkas, “Applying the extended and unscented kalman filters for nonlinear state estimation," in Proceedings of the Inter-eng 2012 Conference, pp. 233-239, Tg Mureş, România, 2012. 


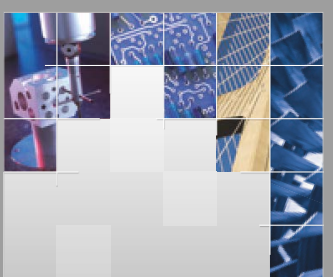

\section{Enfincering}
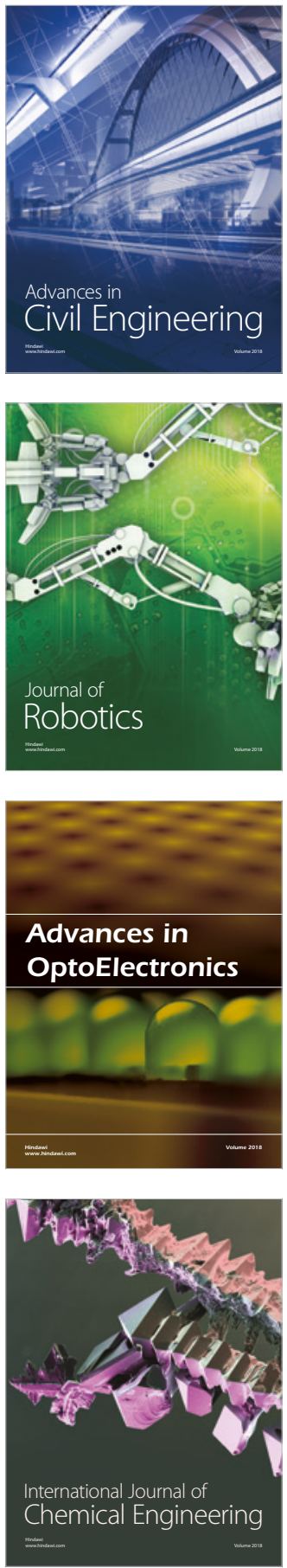

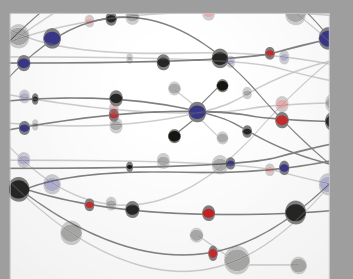

\section{Rotating \\ Machinery}

The Scientific World Journal

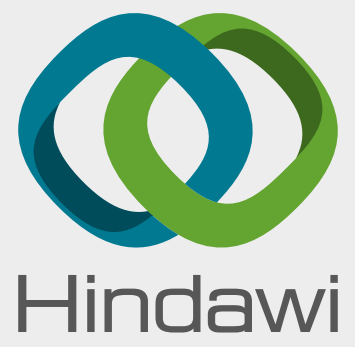

Submit your manuscripts at

www.hindawi.com
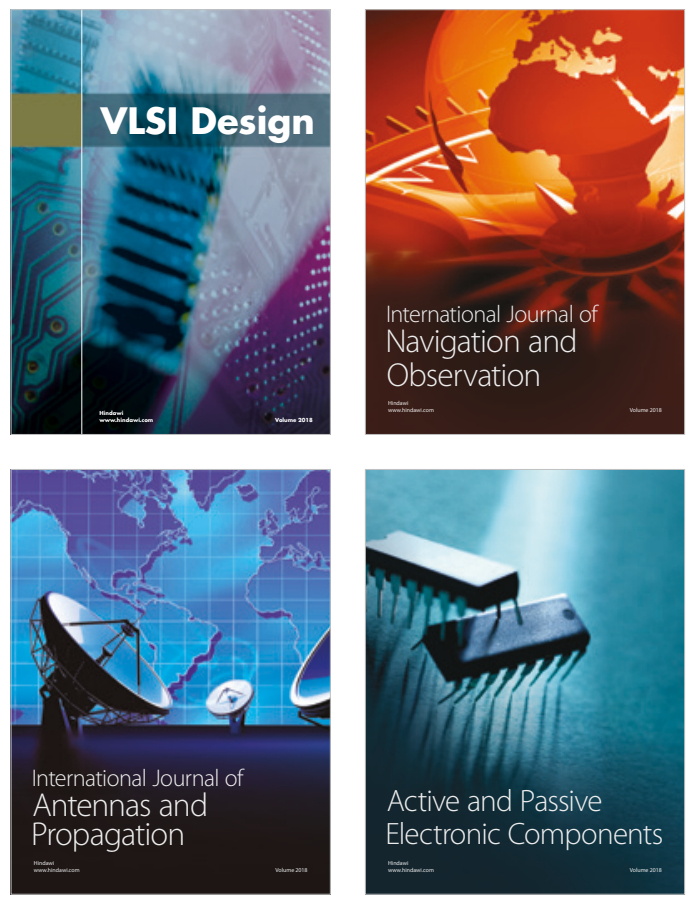
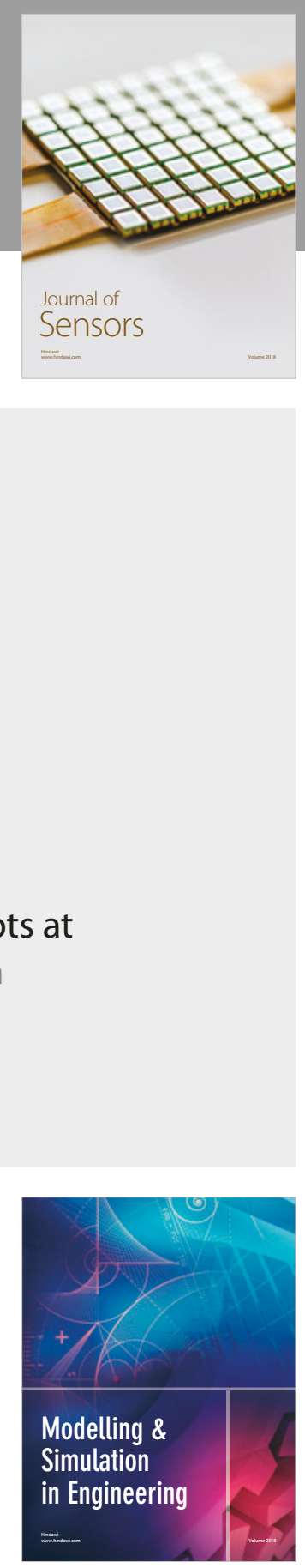

\section{Advances \\ Multimedia}
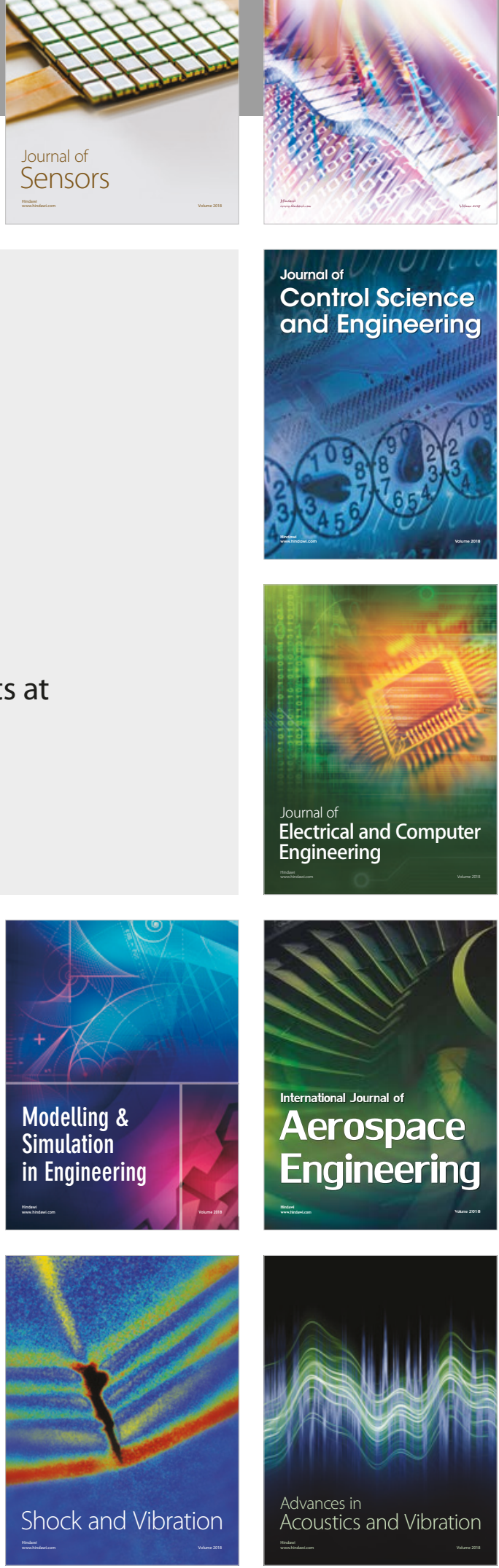